\title{
Synthesis of new biobased linear poly(ester amide)s
}

\author{
Thi Hang Nga Nguyen", Frédéric Balligand ${ }^{2}$, Andreas Bormann², Véronique \\ Bennevault $^{1,3, *}$ and Philippe Guégan ${ }^{1, *}$ \\ ${ }^{1}$ Institut Parisien de Chimie Moléculaire, UMR 8232 CNRS, Sorbonne Université, Paris, France \\ ${ }^{2}$ TechnipFMC, Paris, France \\ ${ }^{3}$ University of Evry, Evry, France
}

\begin{abstract}
In the present work, we investigated the synthesis of new biobased linear aliphatic PEAs with a controlled regicity, in a two steps procedure. First, dioldiamide derivatives were successfully synthesized, then polycondensation reaction using the usual alcohol plus acid reaction was performed. NMR analyses demonstrate that dioldiamide can be synthesized in one step from diacid and ethanolamine condensation with high conversion. A new library of polymers was then synthesized, and characterized. Overall, the reactivity of amine or alcohol or acid functions is investigated by in-depth ${ }^{1} \mathrm{H}$ and ${ }^{13} \mathrm{C}$ NMR versus HSQC NMR analysis. These results can be used to follow the complex evolution of monoesterification or diesterification reactions, monoamidation or diamidation reactions when dicarboxylic acids versus alcohol or amine are reacted. Thermal degradation was examined, and a good stability of all the polymers was evidenced. The thermal properties of the polymers were also analyzed, and high melting temperatures were measured, thanks to the control of the regicity. Comparing the melting and crystallization temperature revealed a fast rate of crystallization, an important feature for polymer melt processing. The solubility behavior of these polymers was found to be close to the one of polyamides, suggesting the use of this new polymers library to replace polyamides in applications where biodegradability of the materials is required.
\end{abstract}

Corresponding author: philippe.guegan@sorbonne-universite.fr, veronique.bennevault@univevry.fr

Keywords: biomass, dicarboxylic acid, dioldiamide monomer, poly(ester amide)s, thermal behaviors 


\section{Introduction}

Poly(ester amide)s have been the subject of extensive research in recent decades [1-3]. Indeed, these polymers have the advantage of both polyamides and polyesters. Polyesters are appreciated for their low environmental impact, thanks to their biodegradability and their possible synthesis from renewable resources [4,5]. However, they may suffer from poor mechanical properties $[6,7]$. On the contrary, polyamides form a network of hydrogen bonds between the amide functions giving them a high cohesive energy density, which results in high mechanical properties [8,9]. However, they are not or only partially biodegradable. Poly(ester amide)s (PEAs) are then likely to combine biodegradability properties with high mechanical and thermal properties [10]. Moreover, the thermal and mechanical properties can be adapted by varying the ester/amide function ratio $[11,12]$.

The first PEAs were synthesized by Carothers in 1932 by the polycondensation of diacids, diols and diamines [13]. Nowadays, different pathways based on ring opening of monomers (depsipeptides [14], cyclic anhydrides with diisopropanolamine [15], lactams / lactones [16], bis(2-oxazolines) with dicarboxylic acids [17]) or acyclic diene metathesis polymerization [18] or spontaneous zwitterionic copolymerization of 2-oxazolines or 2-oxazines with acrylic acid [19] have been developed. Nevertheless, PEAs are usually produced by polycondensation of monomers bearing carboxylic acid, amine, ester, hydroxyl, acyl halide groups via melt polycondensation, solution polycondensation, interfacial polycondensation or solid/liquefied state polycondensation $[1,20]$. In order to produce PEA on a large scale the simplest pathways is the polycondensation of a carboxylic diacid and an amino alcohol. In this case, a repeat unit with an ester and an amide function is produced, but without any control of the amino alcohol insertion into the poly(esteramide), and therefore without control of the polymer microstructure (Fig. 1). The thermomechanical properties are then directly impacted. A higher cohesive energy density is expected from a regular alternating chain microstructure, as illustrated by I. Goodman et al. [21]. Synthetic pathways from prepolymers have also been developed, but most of the studies have led to the synthesis of block copolymers, generally with thermoplastic elastomeric properties [22]. 


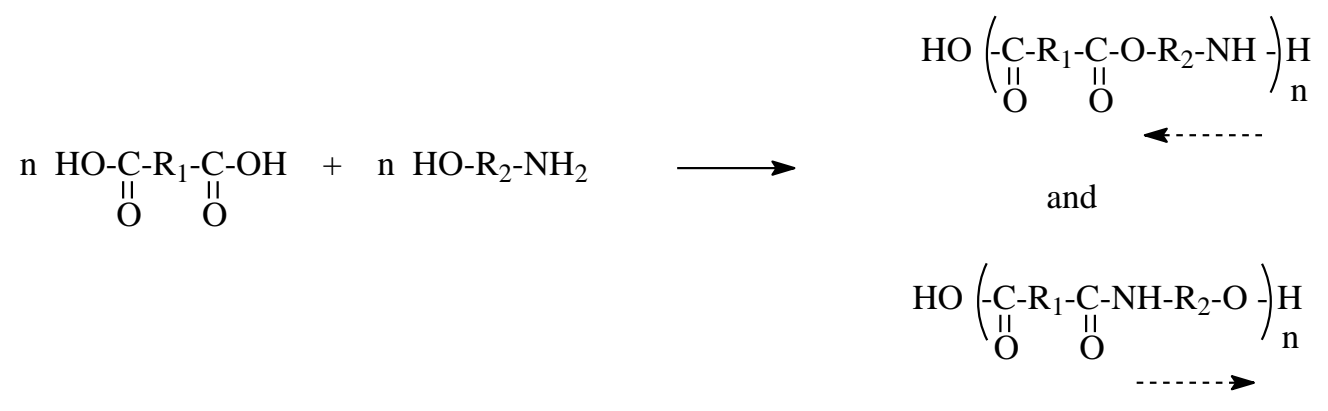

Fig. 1 Different insertion directions of the aminoalcohol during the polycondensation (dotted arrows represent the regicity direction)

Processes for the preparation of aromatic or partially aromatic PEAs being an alternating chain microstructure have been described in some papers, for example by Mansour et al. [23]. These polymers are generally nondegradable. Unfortunately, the preparation of aliphatic polyesteramide is much less described in the literature.

Moreover, nowadays most of the polymers are made from petroleum-based products. The planned depletion of fossil resources and environmental issues urge researchers to find alternatives to replace the petroleum-based monomers and synthesize biodegradable polymers [24]. New or usual chemical intermediate may be then produced from plants including agroresources and lignocellulosic resources (biomass). However, few studies investigated the synthesis of PEA from biobased chemicals allowing a large-scale production. These new biodegradable polymers have to be developed with low production costs, so produced by a straightforward process, but inducing at the same time satisfactory material properties comparable to those of oil-based derivatives. The real challenge is to satisfy all these requirements.

In this work, ethanolamine, aliphatic fatty diacid containing 4 to 14 carbons and the $(\mathrm{Z})$ octadec-9-enedioic acid (D18:1) were investigated as monomers. D18:1 is a natural unsaturated fatty diacid produced by a fungus fermentation of the oleic acid [25]. Succinic acid is a chemical intermediate with high potential, since it leads to various commodity and high-value chemical compounds [26]. Therefore, it is a component of many applications in industry such as in the manufacture of paints, inks, plastics, cosmetics, pharmaceuticals, antifreeze products, pigments, metal processing [27,28]... It may be obtained from starch issued from agro-resources (wheat, corn) or from cellulose / hemicellulose extracted from lignocellulosic resources (wood, plants, agricultural and non-agricultural residues). After different treatment steps, these two processes give glucose allowing the production of succinic acid thanks to a last enzymatic fermentation process. A few companies and industrial 
consortia have begun to develop industrial productions at large scale [29]. Ethanolamine is also a compound widely used in industry. It is used for example as feedstock in the production of corrosion inhibitors, detergents, emulsification agents, polishes, chemical intermediates and to scrub acid gases [30]. The synthesis route to produce biobased ethanolamine consists in converting glucose into L-serine, followed by a subsequent decarboxylation with Pseudomonas putida S12 [31].

The aim of this study is the design of new biobased linear PEA using a simple and efficient process to synthesize polymers with controlled direction of monomer units insertion. First attempts were performed by polycondensing (Z)-octadec-9-enedioic acid with 2,2'-bis(2oxazoline), a non biobased monomer. To fulfill the biobased requirements, new protocol was developed. This innovative protocol consisted in synthesizing dioldiamide monomers in a single step from a biobased diacid and ethanolamine, then the dioldiamide being polymerized with a diacid. The majority of polycondensations was carried out without solvent and effect of different catalysts in particular a green catalyst was investigated. A library of PEA was thus synthesized with variable thermal characteristics.

\section{Experimental section}

\subsection{Materials}

All reagents used in the synthesis, if not specified, were purchased from Sigma-Aldrich (France). 2,2'-bis(2-oxazoline) (purity > 97\%) was purchased from TCI (Belgium) and was used as received. Diacids, ethanolamine were used without further purification, except for the (Z) octadec-9-enedioic acid (D18:1) (COGNIS, Germany). The latter was dispersed in dichloromethane $(100 \mathrm{~g} / \mathrm{L})$, then the insoluble particles eliminated by filtration and the D18:1 collected after evaporation of the solvent.

\subsection{Synthesis of the $(Z)$ octadec-9-enedioyl dichloride}

$7.02 \mathrm{~g}(22.47 \mathrm{mmol})$ of $\mathrm{D} 18: 1$ and $105 \mathrm{~mL}$ of $\mathrm{CH}_{2} \mathrm{Cl}_{2}$ were successively introduced in a 250 mL two neck round bottom flask equipped with a reflux condenser. After dissolution of the product, the solution was cooled at $0^{\circ} \mathrm{C}$ and $5.76 \mathrm{~mL}(67.16 \mathrm{mmol}, 3 \mathrm{eq}$.$) of oxalyl chloride$ was added dropwise under vigorous stirring. The mixture was then stirred at room temperature for 4 hours. The $\mathrm{HCl}$ vapors formed during the reaction were trapped in a solution of $\mathrm{NaOH}(15 \% \mathrm{w} / \mathrm{v})$. At the end of the reaction, the solvent and the excess of oxalyl 
chloride were eliminated using a rotary evaporator to yield to $7.81 \mathrm{~g}$ of pure diacid chloride $(99.5 \%)$.

\subsection{Synthesis of dioldiamide monomers}

The synthesis of N,N'-bis(2-hydroxyethyl)butanediamide (HEBDA) was given as example. The protocol was then adjusted according to the synthesized dioldiamide. Each synthesis is described in Supporting Information (S1).

$9.784 \mathrm{~g}(82.9 \mathrm{mmol})$ of succinic acid (melting point $\left.=188^{\circ} \mathrm{C}\right)$ and $100 \mathrm{~mL}(1.657 \mathrm{~mol}, 20$ eq. $)$ of ethanolamine were initially introduced into a apparatus of $250 \mathrm{~mL}$. The mixture was heated to $160^{\circ} \mathrm{C}$ with stirring. The solution became clear in few minutes. After 5 hours of reaction, the reaction was complete. The reaction medium was then cooled and precipitated in $1 \mathrm{~L}$ of chloroform. The insoluble product was filtered, washed with $500 \mathrm{~mL}$ of fresh chloroform and dried. The expected product was obtained in $78.5 \%$ yield $(13.29 \mathrm{~g})$ with a high purity $(100 \%)$. The purity and structure were confirmed by ${ }^{1} \mathrm{H},{ }^{13} \mathrm{C}$, HSQC NMR and HRMS experiments (SI). The white crystalline product was stable until $205^{\circ} \mathrm{C}$ (value corresponding to $5 \%$ of weight loss $\left.\left(\mathrm{T}_{5 \%}\right)\right)$ and melted at $144^{\circ} \mathrm{C}$.

\subsection{Synthesis of the PEAs}

\section{- Polymerizations from 2,2'-bis(2-oxazoline)}

Polymerizations of D18:1 with 2,2'-bis(2-oxazoline) were conducted in a cylinder flask equipped with a mechanical stirrer under nitrogen using an equimolar ratio between the two monomers. The reaction medium was heated between $140^{\circ} \mathrm{C}$ and $190^{\circ} \mathrm{C}$ from 5 to $98 \mathrm{~h}$ according to the run. A salt bath composed of a mixture of $\mathrm{NaNO}_{3}, \mathrm{NaNO}_{2}$ and $\mathrm{KNO}_{3}$ (respectively 7\%, 40\% and 53\% by weight) was used for heating. After cooling, the resulting polymer was dissolved in $2 \mathrm{~mL}$ of $\mathrm{N}$-methyl-2-pyrrolidone (NMP) and precipitated in methanol. The polymer was filtered then dried at $30^{\circ} \mathrm{C}$ under vacuum for one day.

\section{- Polymerizations based on diacid and dioldiamide}

The synthesis of PEA from D18:1 and (Z) N,N'-bis(2-hydroxyethyl)octadec-9-enediamide (HED18:1DA) was given as example. The protocol was then adjusted according to the diacid, dioldiamide and catalyst used. Each synthesis is detailed in Supporting Information (S2).

The polymerization was carried out in a two steps procedure using an equimolar mixture of D18:1 and HED18:1DA and titanium tetrabutoxide $\left(\mathrm{Ti}(\mathrm{OBu})_{4}\right)$ as catalyst. $1.99 \mathrm{~g}(6.4 \mathrm{mmol})$ of D18:1 and $2.55 \mathrm{~g}(6.4 \mathrm{mmol})$ of HED18:1DA were initially introduced into a stirred two 
necked schlenk glass reactor. The mixture heated to $160^{\circ} \mathrm{C}$ became quickly a clear liquid and was stirred for 2 hours under a stream of nitrogen. Then, a solution of $\operatorname{Ti}(\mathrm{OBu})_{4}$ in toluene was added $\left(0.1 \mathrm{~mol} \%\right.$ of $\mathrm{Ti}(\mathrm{OBu})_{4}$ relative to diacid). During the second step of polycondensation, the reaction mixture was heated to $170^{\circ} \mathrm{C}$ and a dynamic vacuum was applied for $4 \mathrm{~h}$ in order to distil off traces of water. After this reaction time, the mixture was solubilized in $40 \mathrm{~mL}$ of THF and precipitated in $1 \mathrm{~L}$ of $\mathrm{MeOH}$. After filtration and drying, $3.56 \mathrm{~g}$ of polymer was removed (82\%). The polymer was characterized by ${ }^{1} \mathrm{H}$ and ${ }^{13} \mathrm{C} \mathrm{NMR}$ in $\mathrm{CDCl}_{3}$. The molar mass of the polymer was determined by size exclusion chromatography (SEC) in THF using a polystyrene calibration. $M_{\mathrm{n}}$ is equal to $12000 \mathrm{~g} / \mathrm{mol}$ with a dispersity of 1.97. The thermal properties are: $\mathrm{T}_{5 \%}=299^{\circ} \mathrm{C} ; \mathrm{T}_{\mathrm{g}}=-31^{\circ} \mathrm{C} ; \mathrm{T}_{\mathrm{c}}=43.5^{\circ} \mathrm{C} ; \mathrm{T}_{\mathrm{m}}=73.5^{\circ} \mathrm{C}$.

\subsection{Instrumentation}

\section{Size Exclusion Chromatography (SEC)}

The number-average molar mass $\left(M_{\mathrm{n}}\right)$, the weight-average molar mass $\left(M_{\mathrm{w}}\right)$ and the dispersity $(\nexists)$ of the PEAs were determined by size exclusion chromatography (SEC) in dimethylsulfoxyde (DMSO) or methylene chloride $\left(\mathrm{CH}_{2} \mathrm{Cl}_{2}\right)$ or tetrahydrofuran (THF) according to the polymer solubility. The OmniSEC 5.12 software was used for data acquisition and data analysis.

SEC in DMSO: The analyses were performed at $80{ }^{\circ} \mathrm{C}$ in DMSO containing $\mathrm{LiBr}\left(1 \mathrm{~g} . \mathrm{L}^{-1}\right)$ with a flow rate of $0.7 \mathrm{~mL} \cdot \mathrm{min}^{-1}$, using two PSS GRAM $1000 \AA$ columns $(8 \times 300 \mathrm{~mm}$; separation limits: 1 to $\left.1000 \mathrm{~kg} \cdot \mathrm{mol}^{-1}\right)$ and one PSS GRAM $30 \AA(8 \times 300 \mathrm{~mm}$; separation limits: 0.1 to $10 \mathrm{~kg} \cdot \mathrm{mol}^{-1}$ ) coupled to a differential refractive index (RI) detector. Toluene was used as a flow rate marker. $100 \mu \mathrm{L}$ of a polymer solution at 2.5 or $5 \mathrm{mg} \cdot \mathrm{mL}^{-1}$ were injected after filtration through a $0.45 \mu \mathrm{m}$ pore size filter. The molar masses and the dispersity of the PEAs were determined using pullulan standards (5600 g.mol ${ }^{-1}$ to 710000 g.mol ${ }^{-1}$ ).

$\mathrm{SEC}$ in $\mathrm{CH}_{2} \mathrm{Cl}_{2}$ : Size exclusion chromatography (SEC) measurements were carried out on Waters Styragel $5 \mu \mathrm{m}$ columns HR1, HR2, HR3 and HR4 $(7,5 \times 300 \mathrm{~mm}$; separation limits: 0,1 to $600 \mathrm{~kg} \cdot \mathrm{mol}^{-1}$ ) maintained at room temperature and coupled with a modular differential refractive index (RI) detector Viscoteck 3580. Dichloromethane was used as the mobile phase at a flow rate of $1 \mathrm{~mL} \cdot \mathrm{min}^{-1}$ and toluene was used as a flow rate marker. All polymers were injected $(100 \mu \mathrm{L})$ at a concentration of $5 \mathrm{mg} \cdot \mathrm{mL}^{-1}$ after filtration through a $0.45 \mu \mathrm{m}$ pore-size membrane. $M_{n}, M_{\mathrm{w}}$ and $\oslash$ were calculated with a calibration curve based on narrow polystyrene (PS) standards (from Polymer Standard Services), using the RI detector. 
SEC in THF: Polymer molar masses were determined by SEC in THF with three PLGel Mixte C $5 \mu \mathrm{m}$ columns $\left(7.5 \times 300 \mathrm{~mm}\right.$; separation limits: 0.2 to $\left.2000 \mathrm{~kg} \cdot \mathrm{mol}^{-1}\right)$ maintained at $40{ }^{\circ} \mathrm{C}$ coupled with a RI detector Viscotek 3580. THF was used as the mobile phase at a flow rate of $1 \mathrm{~mL} \cdot \mathrm{min}^{-1}$, and toluene was used as a flow rate marker. All polymers were injected $(100 \mu \mathrm{L})$ at a concentration of $5 \mathrm{mg} \cdot \mathrm{mL}^{-1}$ after filtration through a $0.45 \mu \mathrm{m}$ pore-size membrane. The molar masses and the molar mass distributions were determined using a calibration curve based on narrow poly(methyl methacrylate) (PMMA) standards (from Polymer Standard Services).

\section{NMR spectroscopy}

The NMR spectra were recorded on a Bruker (400 MHz) instrument in DMSO-D6 or $\mathrm{CDCl}_{3}$ according to the compound solubility.

\section{Thermogravimetric Analysis (TGA)}

The thermal stability of the monomers and polymers was determined by thermogravimetric analysis using a Q50 analyzer (TA Instruments). The samples (about $10 \mathrm{mg}$ ) were heated from room temperature to $500^{\circ} \mathrm{C}$ with a heating rate of $10^{\circ} \mathrm{C} \cdot \mathrm{min}^{-1}$ in a nitrogen atmosphere. On the basis of TGA thermograms, the temperature corresponding to the 5\% mass loss $\left(\mathrm{T}_{5 \%}\right)$ was determined.

\section{Differential Scanning Calorimetry (DSC)}

The DSC analysis of the samples was performed using a differential scanning calorimeter Q2000 (TA Instruments). The monomers and polymers (5-10 mg) were sealed in aluminum cups. Two different temperature programs were used. Monomers were heated from room temperature to $200^{\circ} \mathrm{C}$ at $20^{\circ} \mathrm{C} \cdot \mathrm{min}^{-1}$; after an isotherm of $2 \mathrm{~min}$, they were cooled down at $20^{\circ} \mathrm{C} \min ^{-1}$ until $-10^{\circ} \mathrm{C}$. Two heating cycles were realized. The melting temperature of monomers was determined on the second rise in temperature. Polymers were heated from $20^{\circ} \mathrm{C}$ to $200^{\circ} \mathrm{C}$ at $20^{\circ} \mathrm{C} / \mathrm{min}$, followed by an isotherm of $2 \mathrm{~min}$, they were then cooled until $80^{\circ} \mathrm{C}$ at $50^{\circ} \mathrm{C} \mathrm{min}{ }^{-1}$. The following heating and cooling were performed at $10^{\circ} \mathrm{C} \mathrm{min}^{-1}$. As for monomers, the glass temperature and melting temperature was measured on the last heating.

\section{Results and discussion}




\subsection{Polycondensation of 2,2'-bis(2-oxazoline) and D18:1}

The synthesis of PEAs from bis(2-oxazoline)s and dicarboxylic acids is known since the 1960s [32, 33]. The reaction involved is an isomerization ring opening mechanism of the oxazoline function. Advantages of this process are that the reaction is not reversible, volatiles products free and it occurs in one step (Scheme 1). Moreover, the polymer microstructure is obviously controlled. In this work, the PEAs were first synthesized from D18:1 and 2,2'-bis(2oxazoline) using an equimolar ratio. Few bis(2-oxazoline) derivatives are commercially available and they are mainly aromatic or substituted in atom number 4 of the oxazoline ring. Many works used aromatic bis(2-oxazoline)s in order to obtain high thermal and chemical stability properties $[17,23,34,35]$. However, the aromatic structure is not consistent with the aimed biodegradability of the PEA and the presence of substituent on the oxazoline ring probably reduces the reactivity of the monomer by steric hindrance [36]. To our knowledge, only one aliphatic compound, the 2,2'-bis(2-oxazoline), is available in large scale, and represents a good opportunity to investigate PEA synthesis via the oxazoline route.

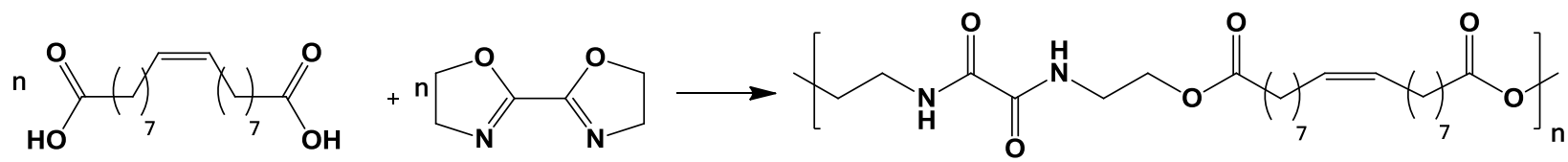

Scheme 1 : Polycondensation of 2,2'-bis(2-oxazoline) and D18:1

Polymerizations were conducted under nitrogen at temperatures above the melting point of D18:1 $\left(\mathrm{T}_{\mathrm{m}}=68^{\circ} \mathrm{C}\right)$, and different operating conditions were investigated (temperature, time). These conditions and the characteristics of the polycondensates are collected in Table 1. Before the polymer precipitation, the conversion of acid functions was estimated by analyzing the reaction medium with a few drops of trichloacetylisocyanate (TAI) by ${ }^{1} \mathrm{H}$ NMR in $\mathrm{CDCl}_{3}$. After reaction with TAI, the protons of the terminal $\mathrm{C}_{2}-\mathrm{CO}_{2} \mathrm{H}$ shift from 2.3 to $2.6 \mathrm{ppm}$, allowing distinguishing unreacted monomer from polymer units. In the tested conditions, the conversion varied from $93 \%$ to $97 \%$. 


\begin{tabular}{cccccccccccc}
\hline Run & $\begin{array}{c}\mathrm{T} \\
\left({ }^{\circ} \mathrm{C}\right)\end{array}$ & $\begin{array}{c}\text { time } \\
(\mathrm{h})\end{array}$ & $\begin{array}{c}\mathrm{p}^{\mathrm{l}} \\
(\%)\end{array}$ & $\begin{array}{c}\mathrm{yield}^{2)} \\
(\%)\end{array}$ & $\begin{array}{c}\mathrm{Mn}^{3)} \\
\left(\mathrm{g} \cdot \mathrm{mol}^{-1}\right)\end{array}$ & $\begin{array}{c}\mathrm{D} \\
\mathrm{T}_{5 \%} \\
\left({ }^{\circ} \mathrm{C}\right)\end{array}$ & $\begin{array}{c}\mathrm{T}_{\mathrm{g}} \\
\left({ }^{\circ} \mathrm{C}\right)\end{array}$ & $\begin{array}{c}\mathrm{T}_{\mathrm{m}} \\
\left({ }^{\circ} \mathrm{C}\right)\end{array}$ & $\begin{array}{c}\Delta \mathrm{H}_{\mathrm{m}} \\
(\mathrm{J} / \mathrm{g})\end{array}$ \\
\hline 1 & 140 & 98 & 93 & 51 & 4300 & 3.8 & 304 & -17 & 114 & 119 & 32.8 \\
\hline 2 & 150 & 6 & $\mathrm{nd}$ & 67 & 5300 & 4.1 & & & 118 & 36.0 \\
3 & 150 & 16 & 91 & 38 & 4100 & 3.2 & 283 & -31 & 111 & 117 & 33.0 \\
4 & 150 & 48 & 97 & 71.5 & 6900 & 6.9 & 309 & -14 & 118 & 42.7 \\
\hline $5^{*}$ & 170 & 5 & 93 & 21 & 3100 & 2.9 & 297 & -29 & 110 & 117 & 42.5 \\
6 & 170 & 8 & 95 & 65 & 4600 & 4.1 & 300 & -22 & 113 & 119 & 29.8 \\
7 & 170 & 16 & 98 & 44 & 7600 & 8.8 & 301 & -26 & 114 & 120 & 22.0 \\
\hline $8^{\#}$ & 180 & 2 & - & - & - & - & - & - & - & - & - \\
$9^{\#}$ & 180 & 5 & - & - & - & - & - & - & - & - & - \\
$10^{\#}$ & 190 & 5 & - & - & - & - & - & - & - & - & - \\
\hline
\end{tabular}

1) determined by ${ }^{1} \mathrm{H}$ NMR

${ }^{2)}$ mass yield after precipitation

${ }^{3)} \mathrm{SEC}$ in $\mathrm{CH}_{2} \mathrm{Cl}_{2}$, polystyrene standards

*: $5 \times 1 \mathrm{~mL}$ of $2,2^{\prime}$-bis(2-oxazoline)

\# crosslinking

Table 1: Polymerization of 2,2'-bis(2-oxazoline) and D18:1 
The first polymerization was conducted at $150^{\circ} \mathrm{C}$ with a reaction time of 6 hours. After precipitation in $\mathrm{MeOH}$, the polymer was analyzed by $\mathrm{NMR}$ in $\mathrm{CDCl}_{3}$ and by size exclusion chromatography in methylene chloride. On the NMR spectrum of the polymer (Fig. 2), we observed units coming from each monomer whose intensities are in agreement with the expected structure of the polymer. This result confirms the opening of the oxazoline rings by the acid functions. The signal of the alpha methylene protons of the ester bond originates from bis-oxazoline appeared at $4.19 \mathrm{ppm}$, while the signal of the methylene protons in alpha of the ester bond originates from D18:1 is located at $2.32 \mathrm{ppm}$ on the NMR spectrum. The SEC number-average molar mass of this polymer is equal to $5300 \mathrm{~g} \cdot \mathrm{mol}^{-1}$ with a quite high dispersity $(\mathrm{D}=4.1)$. At last, the polymer was characterized by DSC, giving a thermogram with an endotherm peak at $118^{\circ} \mathrm{C}$. In order to obtain higher molar mass PEAs with higher thermal characteristics and to understand the reasons of the dispersity value higher than 2, other PEAs with varying reaction time and temperature were synthesized. The results gathered in Table 1 show that the increase of time or heating allowed increasing the molar mass of the polymers, but also induced a higher dispersity without significantly changing the melting temperature of the polymers. According to the analyzed sample, two melting temperatures are sometimes observed, suggesting the formation of crystallites with heterogeneous sizes. All the PEAs are highly crystallized, so that the glass transition was weak and sometimes difficultly characterized. Whatever the PEA considered, the temperature corresponding to $5 \%$ loss in weight is around $300^{\circ} \mathrm{C}$ suggesting that the polymers are thermally stable. 

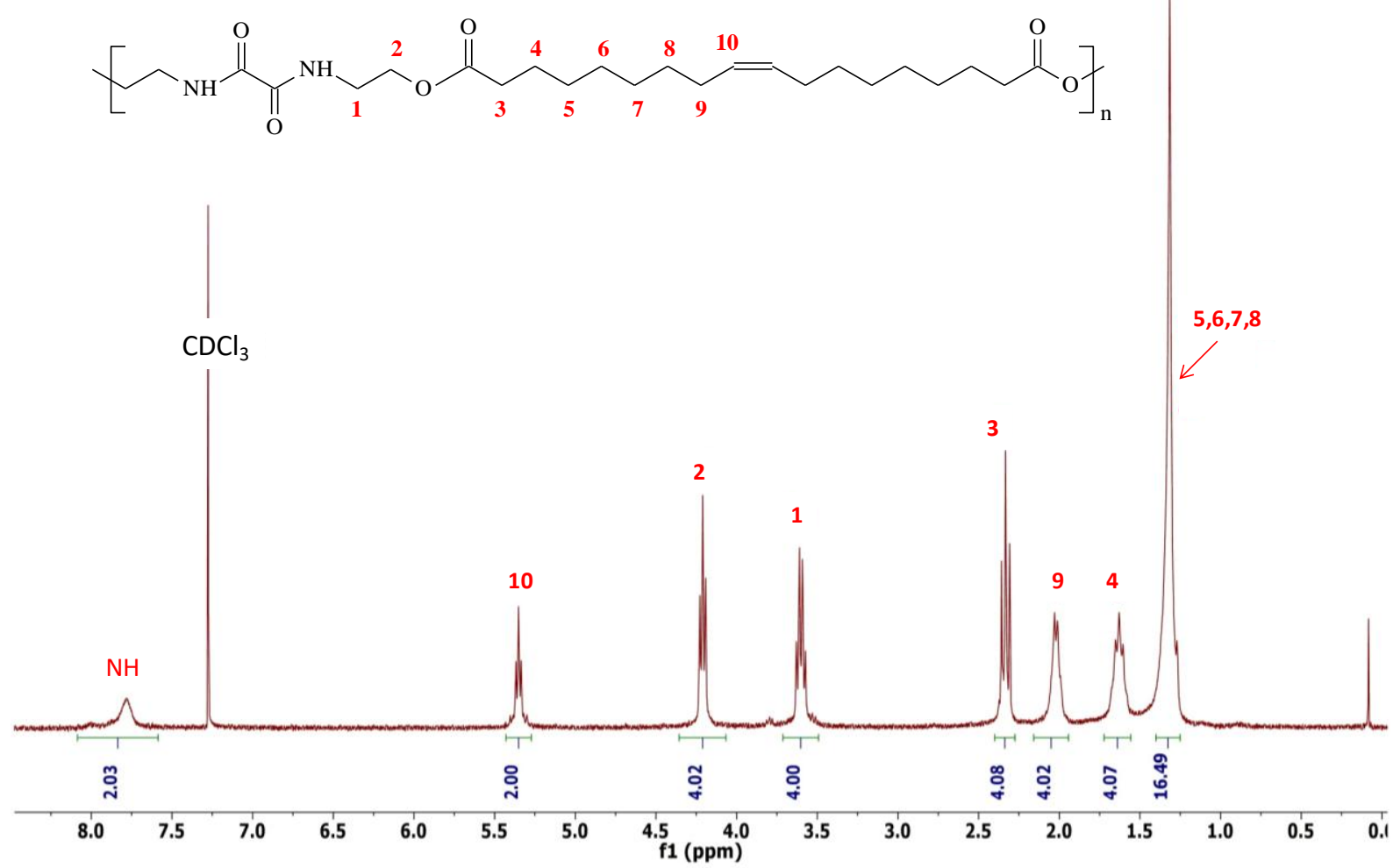

Figure $2:{ }^{1} \mathrm{H}$ NMR spectrum of the PEA synthesized from 2,2'-bis(2-oxazoline) and D18:1 in $\mathrm{CDCl}_{3}$ (run 2, Table 1).

The loss of polymerization control with temperature and reaction time was explained by the existence of a side reaction that may lead to polymer cross-linking in some conditions. Indeed, we observed that all the PEAs synthesized above $180^{\circ} \mathrm{C}$ are insoluble in $\mathrm{N}$-methyl pyrrolidone, even when heating the solution, while polymers synthesized at lower temperature are soluble in this solvent. In a previous paper, Sano showed that the amide group may react with an oxazoline ring inducing its opening and so branching in the polymer structure and cross-linking especially at elevated temperature [37-38]. The reaction is described in Scheme 2. As a consequence, a polymerization was conducted by sequentially introducing 2,2'-bis(2oxazoline) in the reaction medium, in order to limit this side reaction. Unfortunately, a low molar mass polymer with a dispersity of 2.9 was obtained after 5 hours of reaction at $170^{\circ} \mathrm{C}$.

To conclude, our investigated operating conditions did not allow synthesizing high molar mass polymers having a controlled structure to allow high thermal properties. Nevertheless, the synthesized PEAs present a melting temperature of about $120^{\circ} \mathrm{C}$. 


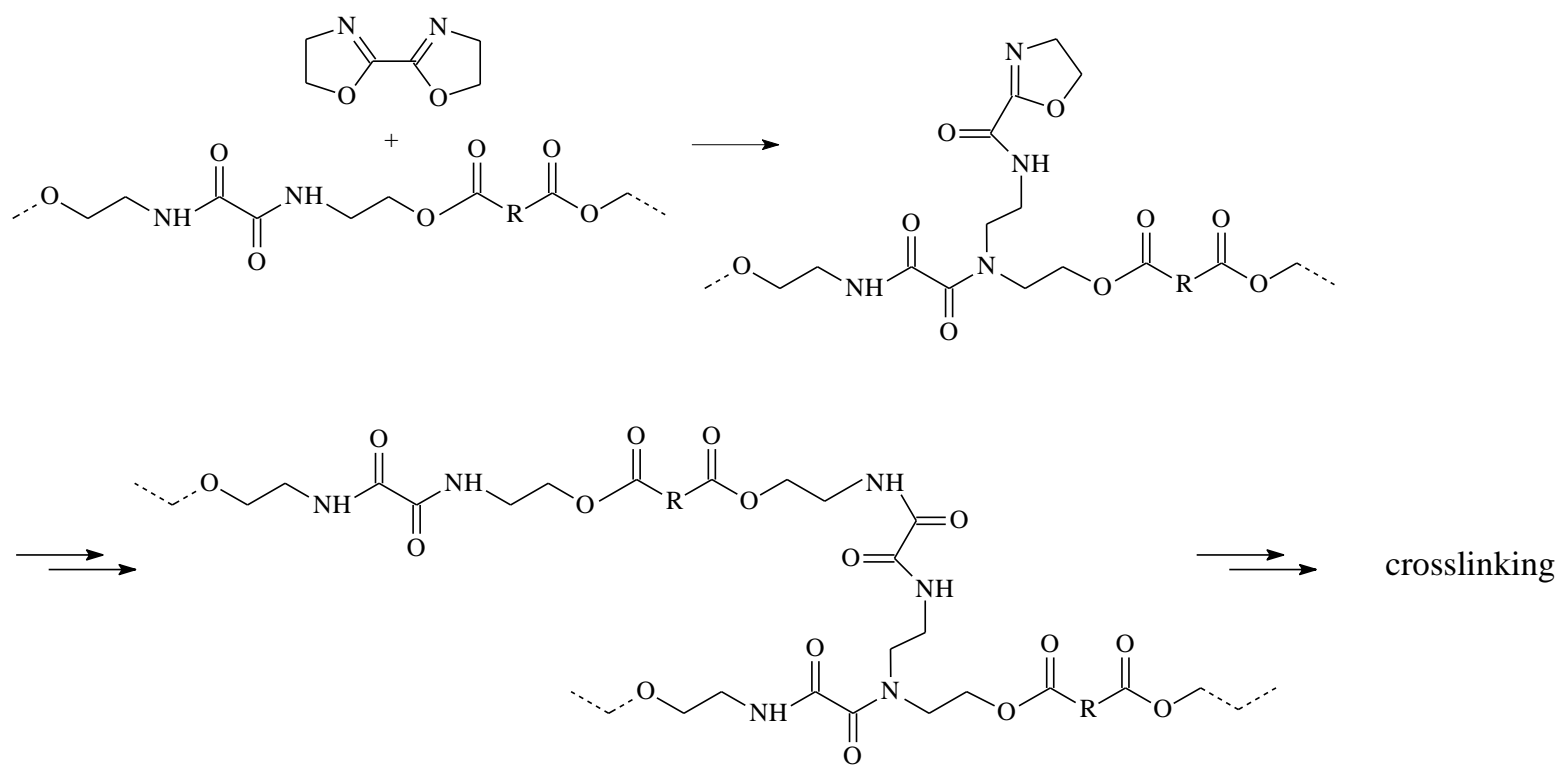

Scheme 2 : Branching and cross-linking reactions

In addition to these polymerizations, some attempts to synthesize a bis(2-oxazoline) derivative from D18:1 were performed, to obtain a fully biobased polymer. First, a synthesis based on a protocol published by D. Kumar et al. [39] was realized. In this approach, it was necessary to synthesize beforehand the acid chloride from D18:1 by reacting the diacid with oxalyl chloride. This reaction conducted in methylene chloride is quantitative and reproducible. The purity of the collected product was shown by ${ }^{1} \mathrm{H}$ and ${ }^{13} \mathrm{C}$ NMR (Fig S3). The second step consisted in stirring the (Z) octadec-9-enedioyl dichloride, triethylamine and ethanolamine in solution in $\mathrm{CH}_{2} \mathrm{Cl}_{2}$ at $20^{\circ} \mathrm{C}$ for $2 \mathrm{~h}$, then for $17 \mathrm{~h}$ after the addition of mesyl chloride at $0^{\circ} \mathrm{C}$. Unfortunately, this process did not allow obtaining the expected bis(2oxazoline) derivative. Therefore, this pathway was split in two steps in order to first confirm the reaction between ethanolamine and $(\mathrm{Z})$ octadec-9-enedioyl dichloride. The different syntheses realized showed that an emulsion occurred, strongly reducing the yield of the expected dioldiamide $(\approx 10 \%)$. Most of the time, mixtures were obtained, that showed the difficulty to control this reaction although different experimental conditions were investigated. The second step of the pathway was then realized with a pure dioldiamide and mesyl chloride. However, this attempt conducted to a dichlorinated compound instead of the expected bis(2-oxazoline) derivative, probably generated according to the mechanism detailed in Figure S4. The formation of this product was highlighted by a ${ }^{13} \mathrm{C}$ NMR analysis (Fig S5). Indeed, the NMR spectrum showed two peaks at $43.73 \mathrm{ppm}$ and $41.16 \mathrm{ppm}$, which are respectively assigned to the alpha methylene carbons of the amide function and to the 
methylene carbons bearing the chlorine atoms. In the case of bis(2-oxazoline) residus, the chemical shifts of these carbons would be about $68 \mathrm{ppm}$ and $54 \mathrm{ppm}$. The ${ }^{1} \mathrm{H}$ NMR spectrum of the synthesized product was also given in supporting information (Fig S6). The assignments of NMR spectra of the (Z) N,N'-bis(2-chloroethyl)octadec-9-enediamide were confirmed by a HSQC experiment.

\subsection{Synthesis of dioldiamides in bulk}

To circumvent the previous difficulties, a simplified approach was developed. Thus, the $(Z)$ N,N'-bis(2-hydroxyethyl)octadec-9-enediamide (HED18:1DA) was successfully synthesized by heating D18:1 with an excess of ethanolamine (20 eq.) without solvent (Scheme 3). As a consequence, ethanolamine behaves as a solvent and a reagent. The reaction was conducted at $140^{\circ} \mathrm{C}$ for $16 \mathrm{~h}$. The final product was then collected by recrystallization in ethanol. This new pathway allowed obtaining a pure colorless product with a high yield (about 80\%). This encouraging result is consistent with a scale up of the overall process objective with low number of steps and improved yields. The absence of solvent in the process, in particular chlorinated solvent, is also a positive point. The purity of HED18:1DA was shown by ${ }^{1} \mathrm{H}$ and ${ }^{13} \mathrm{C}$ NMR (Fig. 3 and S7) and HSQC NMR analyses. In comparison with the proton NMR spectrum of D18:1, three new signals appeared at 7.73 ppm, 3.37 ppm and 3.09 ppm, which are respectively assigned to $\mathrm{NH}$ protons of the amide functions and to methylene protons of ethanolamine residue covalently linked to the carbon chain of D18:1. A shift of the signals corresponding to protons 8 (alpha protons of $\mathrm{C}=\mathrm{O}$ group) to high field was also observed, highlighting the reaction success between the acid function and ethanolamine. Moreover, the intensity ratios of peaks belonging to protons from D18:1 and to protons from ethanolamine residue are consistent with the expected structure of the dioldiamide, which showed that the reaction is quantitative. All the signals are assigned and no additional peak was detected, confirming the purity of the product.

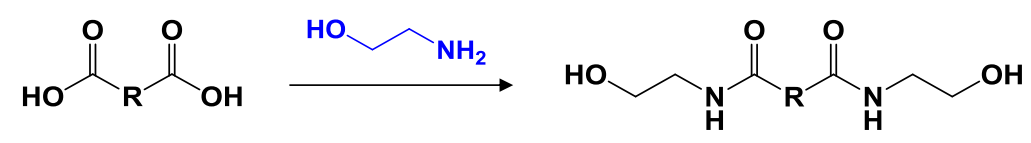

Scheme 3 : Synthesis of dioldiamides 


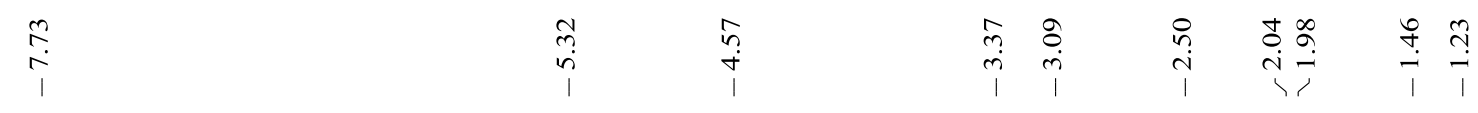
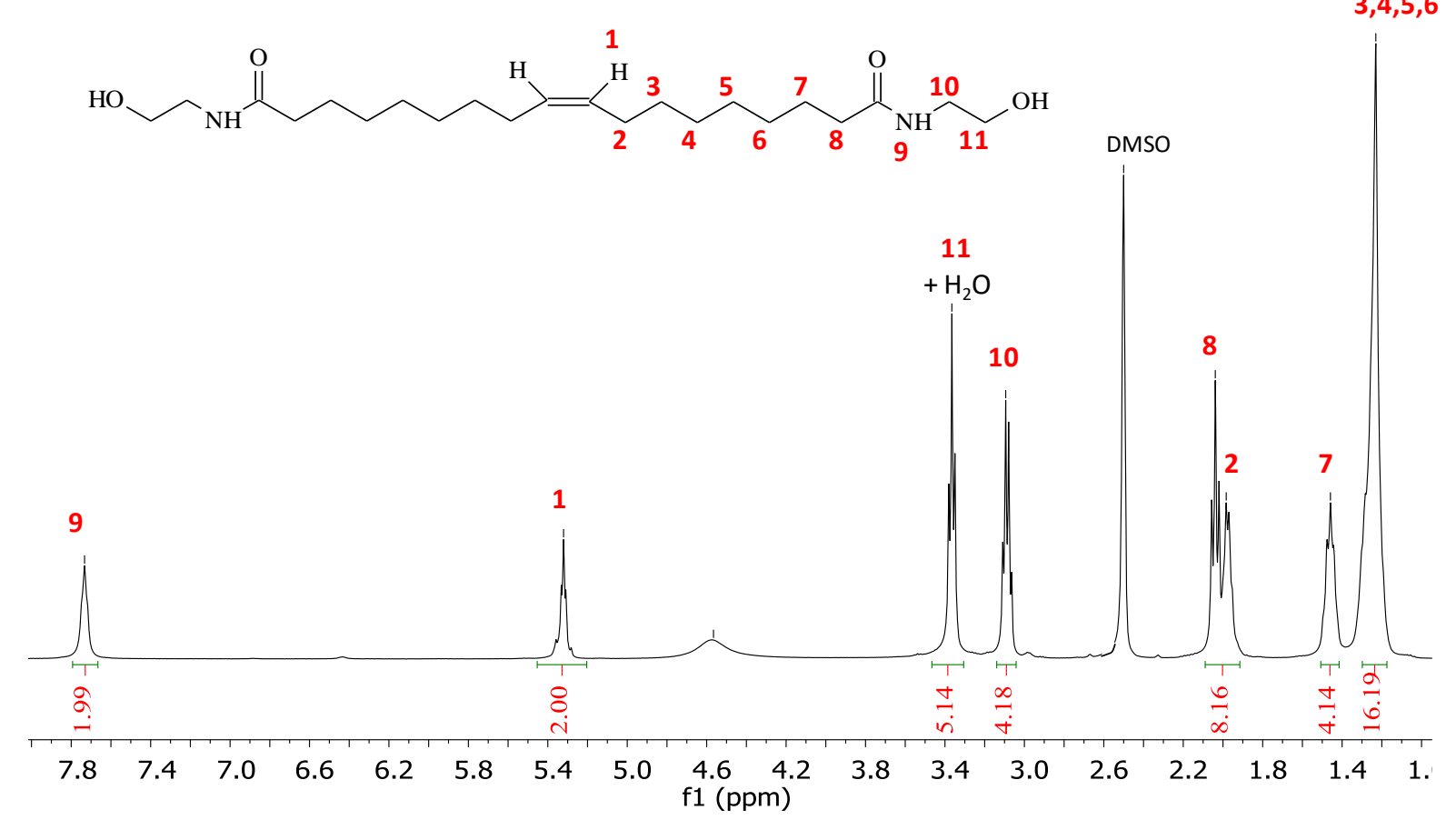

Figure 3: ${ }^{1} \mathrm{H}$ NMR spectrum of (Z) N,N'-bis(2-hydroxyethyl)octadec-9-enediamide in DMSO-D6

This synthesis was repeated using various renewable diacids containing from 4 to 14 carbons, in order to obtain a library of dioldiamine monomers. The new strategy was then to polycondensate these monomers with diacids in order to synthesize PEA with regular alternating chain microstructure, likely to have high mechanical and thermal properties.

First, the reaction was realized with succinic acid. Similar results were obtained, since pure $\mathrm{N}, \mathrm{N}$-bis(2-hydroxyethyl)butanediamide (HEBDA) was collected after the recristallization step, as shown by the NMR spectra (Fig 4 and S8). Once again, it was noticed an upfield shift for the protons close to the modified functions. The yield was highly dependent on the chosen solvent to recristallize and wash the final product on the filter. Using ethanol, only $35 \%$ of diodiamide was obtained, while a recristallization in chloroform allowed increasing the yield up to $78.5 \%$ without modifying the purity of the monomer. This result was explained by a partial solubility of HEBDA in ethanol. 
In order to optimize the reaction time, a kinetic study was conducted. This study was performed at $140^{\circ} \mathrm{C}$ and $160^{\circ} \mathrm{C}$. Samples of the reaction medium were then taken over time and analyzed by ${ }^{1} \mathrm{H}$ NMR. The conversion was estimated by comparing the intensity of the signals corresponding to the alpha methylene protons of the carbonyl group before and during the reaction (Fig S9). As it can be seen in Figure 5, the reaction was obviously faster at $160^{\circ} \mathrm{C}$. A complete reaction was observed only after 5 hours at $160^{\circ} \mathrm{C}$, while $100 \%$ conversion is achieved after 18 hours for the reaction at $140^{\circ} \mathrm{C}$. In the two experiments, the purity of the final dioldiamide is the same. Therefore, the next syntheses with the different diacids were realized at $160^{\circ} \mathrm{C}$. The same methodology was applied in order to evaluate the reactivity of each tested diacid. Figure 6 shows that the contained carbon number in the diacid impacts the reaction rate. Overall, the lower the carbon number, the higher the rate is except for D18:1 which has a particular structure due to the unsaturation. Therefore, this study allowed determining the required duration to obtain a complete conversion of the acid functions for each compound, that ranges between $5 \mathrm{~h}$ and $30 \mathrm{~h}$. The synthesis of N,N'-bis(2hydroxyethyl)-1,14-tetradecanediamide was also performed in this work, the end of the reaction being estimated only by few samples (not reported in Fig. 6). The structure of each dioldiamide and its purity were confirmed by ${ }^{1} \mathrm{H}$ and ${ }^{13} \mathrm{C}$ NMR (Fig. S10 to S14).
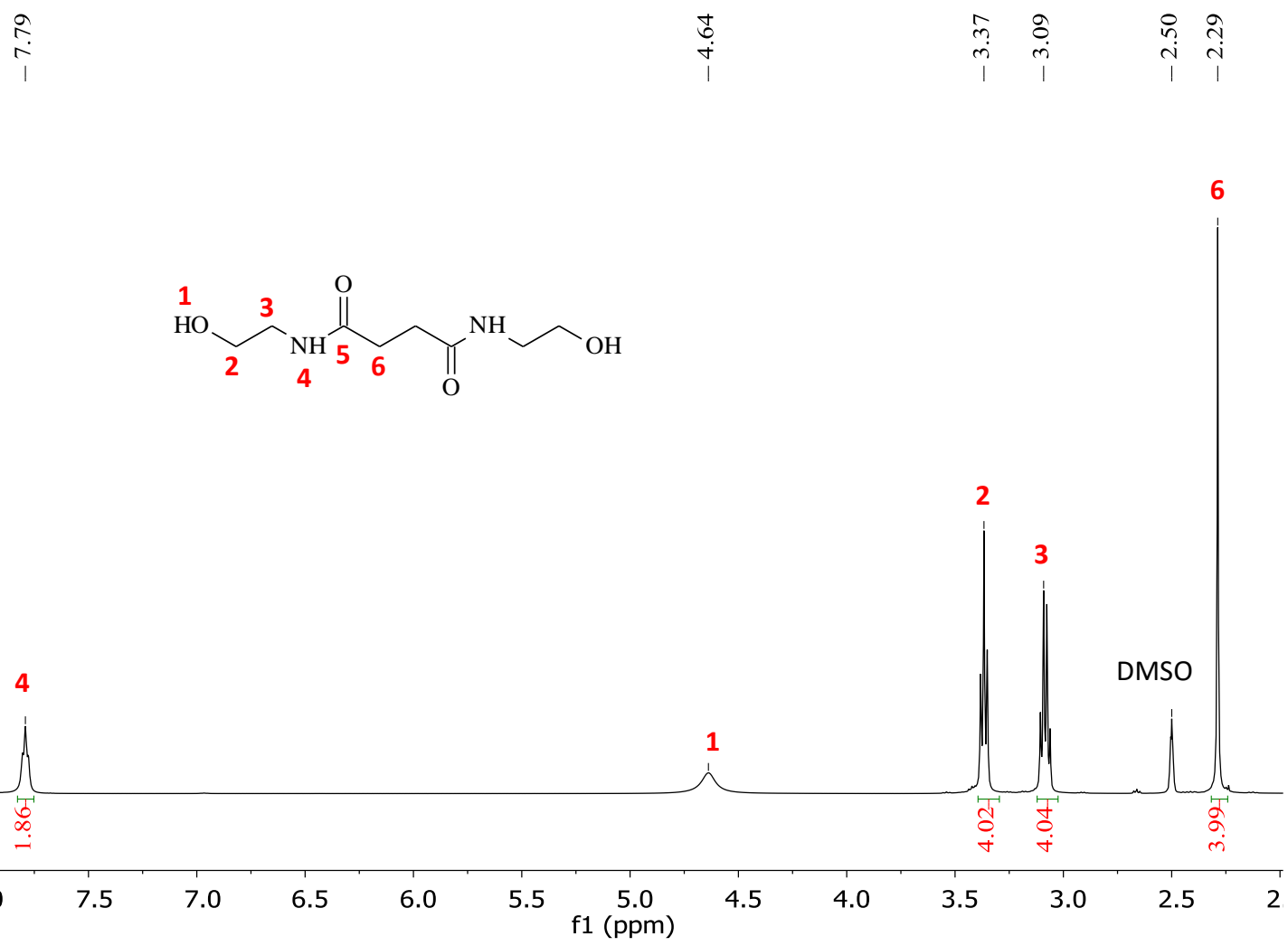

Figure 4: ${ }^{1} \mathrm{H}$ NMR spectrum of N,N'-bis(2-hydroxyethyl)butanediamide (HEBDA) in DMSO-D6 


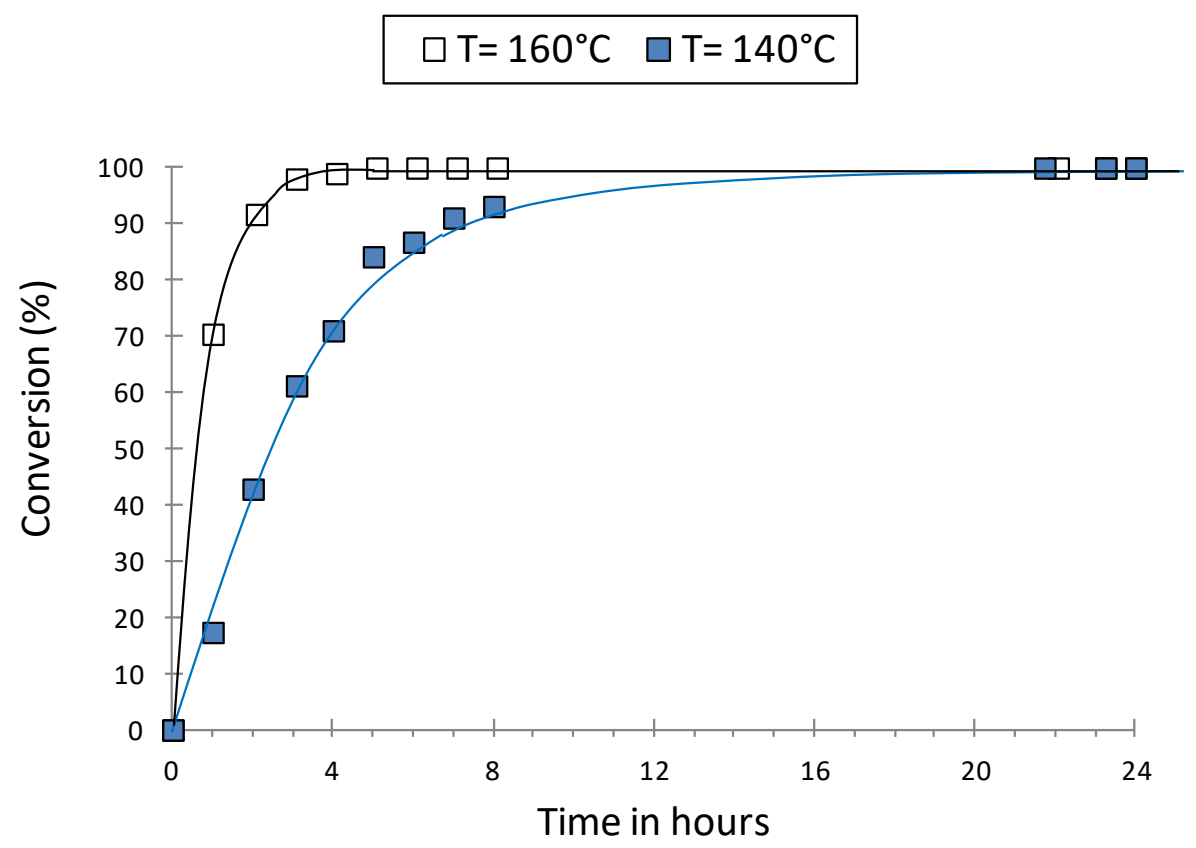

Figure 5: Synthesis of HEBDA : kinetic study at $140^{\circ} \mathrm{C}$ and $160^{\circ} \mathrm{C}$.

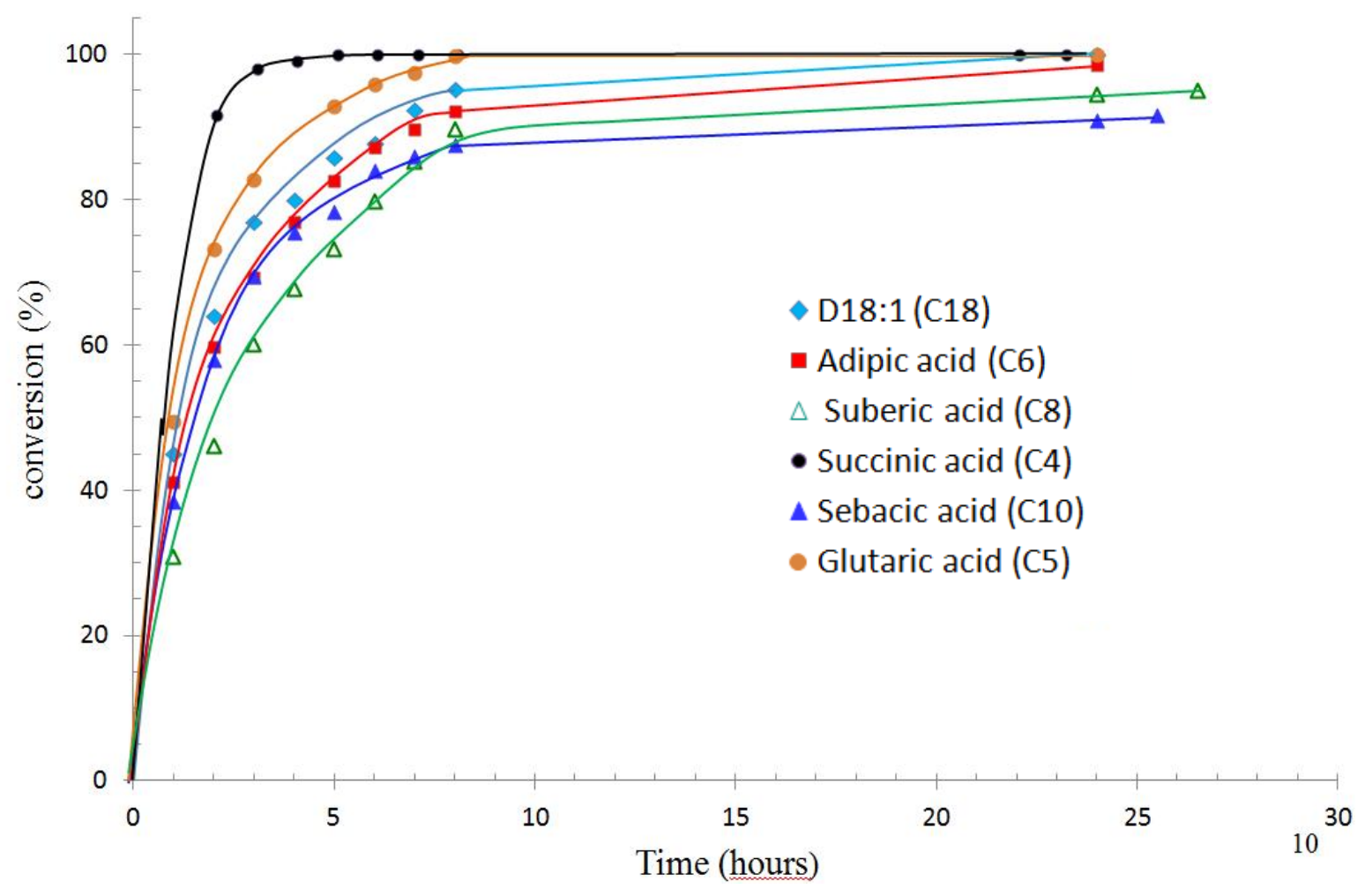

Figure 6: kinetic study of the amidation reaction of various bio-sourced diacid at $160^{\circ} \mathrm{C}$. 
These compounds were then characterized by Thermogravimetric Analysis (TGA) and Differential Scanning Calorimetry (DSC). The results gathered in Table 2 showed that all the dioldiamides are thermally very stables. Indeed, all the temperatures corresponding to a 5\% weight loss $\left(\mathrm{T}_{5 \%}\right)$ exceeded $200^{\circ} \mathrm{C}$ and the monomer stability increases with the carbon content in the compound. Thus, HED18:1DA presents a $\mathrm{T}_{5} \%$ equal to $294.1^{\circ} \mathrm{C}$. Concerning the melting temperatures, the values range from $116.7^{\circ} \mathrm{C}$ to $155.8^{\circ} \mathrm{C}$. Except for the dioldiamides synthesized from succinic acid and D18:1, an increase of $\mathrm{T}_{\mathrm{m}}$ was observed with the number of carbons contained in the compound.

To conclude, this study showed that these monomers could be polymerized by a process in melt in a temperature range between $160^{\circ} \mathrm{C}$ and $170^{\circ} \mathrm{C}$ without any degradation.

\begin{tabular}{|c|c|c|c|}
\hline Dioldiamide & Dioldiamide synthesized from & $\mathrm{T}_{5 \%}\left({ }^{\circ} \mathrm{C}\right)$ & $\mathrm{T}_{\mathrm{m}}\left({ }^{\circ} \mathrm{C}\right)$ \\
\hline HEBDA & succinic acid (C4) & 205.1 & 143.9 \\
\hline HEPDA & glutaric acid (C5) & 252.8 & 116.7 \\
\hline HEHDA & adipic acid (C6) & 260.7 & 135.2 \\
\hline HEODA & suberic acid (C8) & 271.1 & 140.6 \\
\hline HEDDA & sebacic acid (C10) & 279.6 & 146.1 \\
\hline HETDDA & tetradecanedioic acid (C14) & 285.0 & 155.8 \\
\hline HED18:1DA & D18:1 & 294.1 & 118.7 \\
\hline
\end{tabular}

$\mathrm{T}_{5 \%}=$ temperature corresponding to a $5 \%$ mass loss

$\mathrm{T}_{\mathrm{m}}=$ melting temperature

Table 2: Thermal characteristics of the dioldiamides

\subsection{Polycondensation of the dioldiamides and diacids in bulk}

\subsubsection{Synthesis}

The synthesis of PEAs was performed by reacting a dioldiamide and generally the diacid corresponding to the dioldiamide, with an initial molar ratio equal to 1 . The polymerizations catalyzed by $\mathrm{Ti}(\mathrm{OBu})_{4}$ were conducted in two steps (runs 1 to 7 , Table 3). First, the monomers were heated at $160^{\circ} \mathrm{C}$ for 2 hours under nitrogen, then the catalyst was added and the reaction medium was heated at $170^{\circ} \mathrm{C}$ under vacuum for 4 hours. After cooling of the reaction medium, the latter was solubilized in a small amount of solvent (THF, DMSO, NMP according to the solubility of the polymer) and precipitated in cold methanol. The yields were 
high ( $80 \%$ to $100 \%$ ) when polymerizing monomers with a high carbon number (runs 4 to 6 ), and were lower for the other monomers (10\% to $30 \%)$. In our hands, polymerization of succinic acid-based monomers conducted to surprising low yields. More efforts will be devoted to this part to increase that yield in the future for scaling-up purpose. An attempt of polycondensation realized with 2 different diacids (succinic acid and D18:1) and their counterparts led to an intermediate yield $(\approx 20 \%)$ (run 7). According to the solubility of the polymer, the PEAs were analyzed by NMR in DMSO or $\mathrm{CDCl}_{3}$. The latter was used for PEAs synthesized from high molar mass monomers (sebacic acid and D18:1). For the other PEAs having a higher cohesive energy density, it is necessary to use a solvent more polar to dissolve the polymer. However, the solubilization is sometimes limited to low concentration and for some polymers (run 1 and 5) their lack of solubility in usual solvent was problematic for theirs characterizations. For example, the PEA synthesized from $\mathrm{C} 14$ diacid has to be dissolved in trifluoroacetic acid to be analyzed by NMR. No SEC characterization can be performed for this sample and for run 1. 


\begin{tabular}{|c|c|c|c|c|c|c|c|c|c|c|}
\hline Run & Acid & $\begin{array}{l}\text { Dioldiamide } \\
\text { from diacid }\end{array}$ & $\begin{array}{c}\text { Yield } \\
(\%)\end{array}$ & $\begin{array}{c}M_{\mathrm{n}} \\
\left(\mathrm{g} \cdot \mathrm{mol}^{-1}\right)\end{array}$ & Đ & $\begin{array}{l}\mathrm{T}_{5 \%} \\
\left({ }^{\circ} \mathrm{C}\right)\end{array}$ & $\begin{array}{c}\mathrm{T}_{\mathrm{g}} \\
\left({ }^{\circ} \mathrm{C}\right)\end{array}$ & $\begin{array}{c}\mathrm{T}_{\mathrm{c}} \\
\left({ }^{\circ} \mathrm{C}\right)\end{array}$ & $\begin{array}{c}\mathrm{T}_{\mathrm{m}} \\
\left({ }^{\circ} \mathrm{C}\right)\end{array}$ & $\begin{array}{l}\Delta \mathrm{H}_{\mathrm{m}} \\
(\mathrm{J} / \mathrm{g})\end{array}$ \\
\hline $1^{\text {a) }}$ & $\mathrm{C} 4$ & $\mathrm{C} 4$ & 11 & nd & nd & 262 & -5 & 41 & 158 & 149.6 \\
\hline $2^{\text {a) }}$ & C6 & C6 & 29 & $8500^{\mathrm{e})}$ & $1.73^{\mathrm{e})}$ & 268 & -14 & 102 & 122 & 37.7 \\
\hline $3^{\text {a) }}$ & $\mathrm{C} 8$ & $\mathrm{C} 8$ & 19 & $4400^{\mathrm{e})}$ & $1.38^{\mathrm{e})}$ & 263 & -11 & 105 & 137 & 44.5 \\
\hline $4^{\text {a) }}$ & $\mathrm{C} 10$ & $\mathrm{C} 10$ & 79 & $10000^{\mathrm{e})}$ & $1.60^{\mathrm{e})}$ & 266 & -27 & 106.5 & 130 & 41.8 \\
\hline $5^{\text {a) }}$ & $\mathrm{C} 14$ & $\mathrm{C} 14$ & 100 & nd & nd & 283 & nd & 97 & 133 & 37.0 \\
\hline $6^{\text {a) }}$ & D18:1 & D18:1 & 82 & $12000^{\mathrm{f})}$ & $1.97^{\mathrm{f})}$ & 299 & -31 & 43.5 & 73.5 & 39.7 \\
\hline $7^{\mathrm{a}, \mathrm{d})}$ & $\begin{array}{c}\text { C4 } \\
\text { D18: } 1\end{array}$ & $\begin{array}{c}\text { C4 } \\
\text { D18:1 }\end{array}$ & 21 & nd & nd & 284 & -34 & 26 & 67 & 35.6 \\
\hline $8^{\text {b) }}$ & D18:1 & D18:1 & 41 & $10200^{f)}$ & $1.67^{\mathrm{f})}$ & 301 & -33 & 29 & 67 & 41.2 \\
\hline $9^{\text {b) }}$ & $\mathrm{C} 4$ & D18:1 & 13 & $6600^{f)}$ & $1.24^{\mathrm{f})}$ & 293 & -36 & $\begin{array}{r}-12 \\
22\end{array}$ & 59 & 42.4 \\
\hline $10^{c)}$ & $\mathrm{C} 4$ & $\mathrm{C} 4$ & 9 & nd & nd & & -11 & 38 & 152 & 110.8 \\
\hline
\end{tabular}

${ }^{\text {a) }} \mathrm{Ti}(\mathrm{OBu})_{4}, 1^{\text {rst }}$ step: $160^{\circ} \mathrm{C}, 2 \mathrm{~h}$ under $\mathrm{N}_{2}, 2^{\text {nd }}$ step: $170^{\circ} \mathrm{C}, 4 \mathrm{~h}$ under vacuum

b) $\mathrm{TBD}, 1^{\text {rst }}$ step: $160^{\circ} \mathrm{C}, 2 \mathrm{~h}$ under $\mathrm{N}_{2}, 2^{\text {nd }}$ step: $190^{\circ} \mathrm{C}, 3 \mathrm{~h}$ under vacuum

${ }^{\text {c) }} \mathrm{CHTD}, 140^{\circ} \mathrm{C}, 1 \mathrm{~h}$ then $160^{\circ} \mathrm{C}, 2 \mathrm{~h}$ under $\mathrm{N}_{2}$

d) copolymerization of four monomers (C4 and D18:1 diacids and their dioldiamide counterparts, molar ratio 1/1/1/1)

e) SEC in DMSO, pullulan standards

${ }^{\mathrm{f})} \mathrm{SEC}$ in THF, polystyrene standards

Table 3: Polycondensations of a dioldiamide with a diacid 
The ${ }^{1} \mathrm{H}$ and ${ }^{13} \mathrm{C}$ NMR spectra corresponding to two PEAs resulting from adipic acid or D18:1 are shown respectively in Figure 7 and S15 for illustration. Compared to the proton spectrum of the N,N'-bis(2-hydroxyethyl)hexanediamide (Fig. S10), two new peaks at $2.29 \mathrm{ppm}$ and $1.52 \mathrm{ppm}$ were observed on the polymer spectrum (Fig. 7) and were assigned to the methylene protons from diacid units in the alpha- and beta- position with respect to the ester function (protons 6' and 7'). It is also noted a low field shift of the methylene protons of the amino alcohol residues located in the alpha- and beta- position of the ester function. Thus, the protons 2 shifts from $3.38 \mathrm{ppm}$ to $3.99 \mathrm{ppm}$, and the protons 3 from $3.10 \mathrm{ppm}$ to $3.25 \mathrm{ppm}$. While the protons 7 and 7' have close chemical shifts, the corresponding carbons signals are clearly separated. A reliable assignment of all carbon peaks could be performed thanks to an HSQC NMR experiment (Fig. S16), which showed that, contrary to the expectations, the chemical shift of the ester carbons are less deshielded than the amide carbons, while the opposite result was observed in proton NMR. Thus, the chemical shifts of the carbons 6' and 7' are lower than ones of the carbons 6 and 7. Similar observations can be done concerning the other PEAs. To conclude, these different observations confirmed the formation of ester bonds in the polymer chains by reaction of the acid and alcohol ends of each monomer. The intensity ratios of the different signals in proton NMR are consistent with the expected structure of the PEAs. The PEAs are then characterized by Size Exclusion Chromatography in THF or in DMSO according to the solubility of the polymer. The molar masses range from 4400 g.mol ${ }^{-1}$ to 12000 g.mol ${ }^{-1}$ with a dispersity between 1.4 and 2.0. The SEC chromatogram of run 4 (Table 3) is given as example in Supporting Information (Fig S17.) 

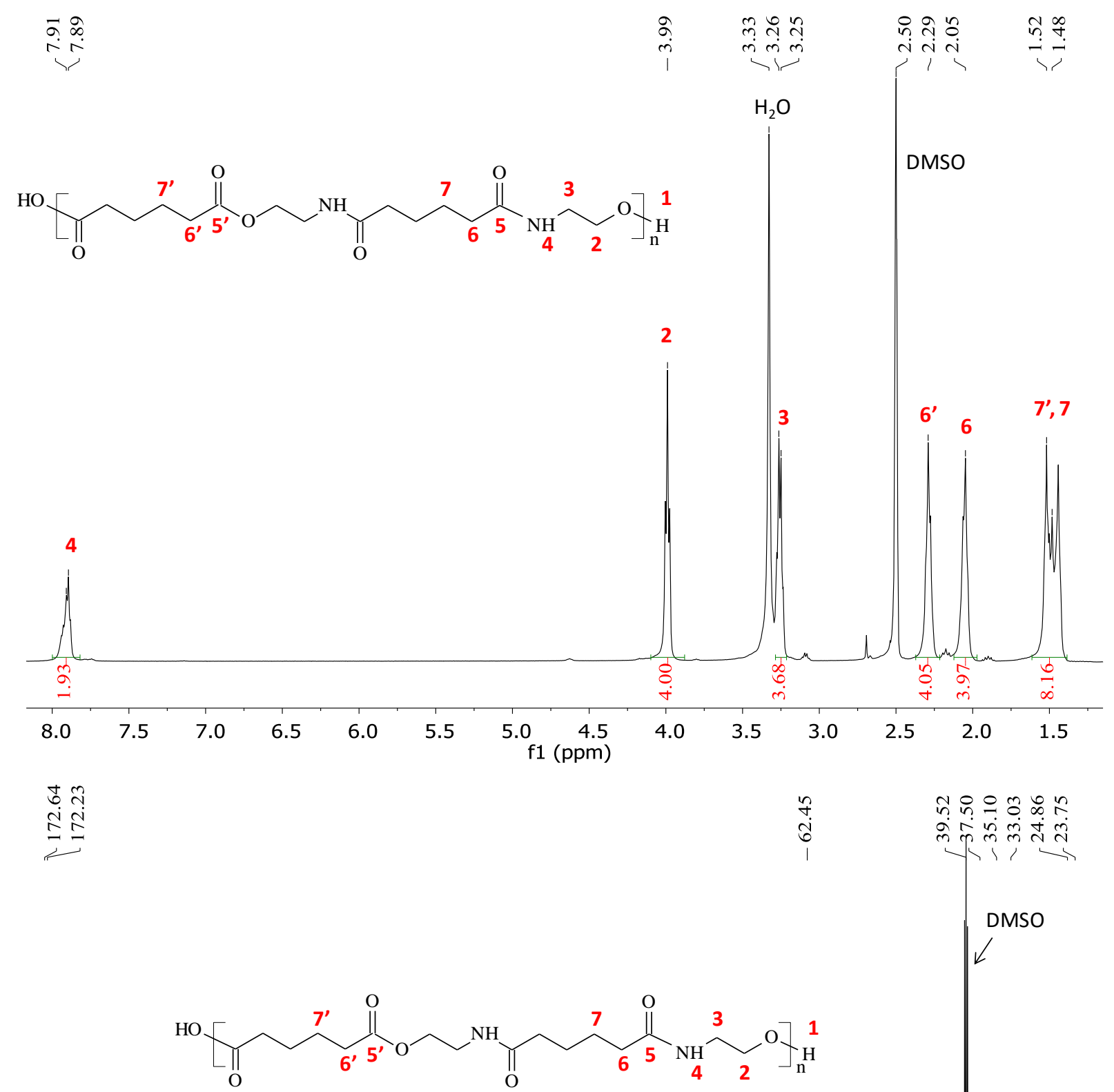

DMSO

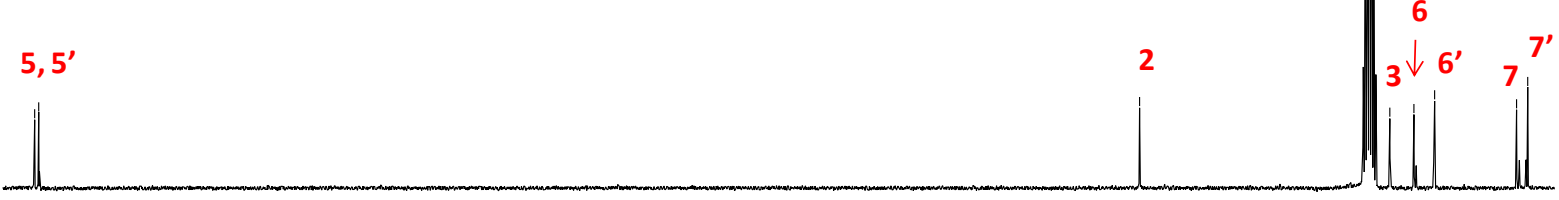

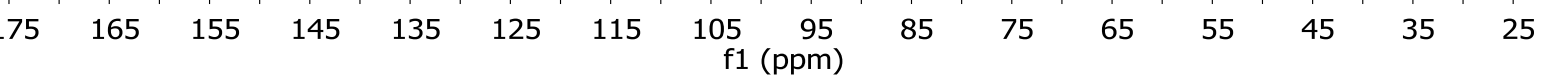

Figure 7: ${ }^{1} \mathrm{H}$ and ${ }^{13} \mathrm{C}$ NMR spectra of PEA resulting from adipic acid and HEHDA in DMSOD6. 


\subsubsection{Thermal properties}

The thermal properties of the polymers were then evaluated by TGA and DSC. The Figure 8 presents the decay of the remaining weight with temperature of the PEAs that were heated from room temperature to $500^{\circ} \mathrm{C}$ at a heating rate of $10^{\circ} \mathrm{C} \cdot \mathrm{min}^{-1}$. It shows that the decomposition rate of the polymers depends on the polymers composition. PEAs synthesized from $\mathrm{C} 4$ and $\mathrm{C} 6$ diacids first degrade, then the polymers based on C8, C10 and C14 and the most stable polymer corresponds to the one synthesized from D18:1. However, all the polymers can be considered as thermally stable since all the $\mathrm{T}_{5 \%}$ are higher than $260^{\circ} \mathrm{C}$, the maximum value being about $300^{\circ} \mathrm{C}$ (Table 3). In each thermogram, two degradation steps appeared. However, for some samples, a first weight loss occurs below $100^{\circ} \mathrm{C}$ and is attributed to a loss of a small amount of combined water. Then, two important decomposition steps occurred, although the last one is much less intense. The second decomposition step was very low for the PEA from succinic acid, but became more acute with the increase of carbon content in the PEA. According to literature [40,41], the first stage of decomposition was assigned to the cleavage of the ester bonds, and the second to one of the amide bonds. T. Fey et al. [42] showed that the thermal degradation of PEA synthesized from succinic anhydride and amino alcohols $\left(\mathrm{H}_{2} \mathrm{~N}-\left(\mathrm{CH}_{2}\right)_{\mathrm{x}} \mathrm{-OH}\right.$ with $\mathrm{x}=2$ to 6$)$ resulted in the formation of $\mathrm{N}$ hydroxyalkyl imides by a nucleophilic attack of the amide nitrogen to the neighboring ester carbonyl group through an intramolecular reaction. In the case of PEA resulting from adipic anhydride and amino alcohols, they showed that cyclic ester amides (CEA) were produced by 2 possible pathways, either a ring enlargement of the $\mathrm{N}$-hydroxyalkyl imides (HAI) or a nucleophilic attack of the PEA hydroxyl end group at the ester carbonyl group [43]. These different results, depending on the used anhydride, were explained by the different stability of the cyclic compounds. Theoretical calculations suggest that the CEA from ethanolamine $(\mathrm{x}=2)$ is not produced, since less stable than HAI and it is confirmed by experiment. I. Villuendas et al. $[44,45]$ compared the thermal and hydrolytic degradation of syndioregic and isoregic PEAs, such as polymers prepared from succinic acid and 6-amino-1-hexanol. They showed the higher stability of the syndioregic samples compared to their isoregic counterparts, highlighting that the regicity i.e. the relative orientation of the monomeric units along the polymer chain is a major factor in the degradation process. Once again, the formation of imides by an intramolecular cyclization was proved and this mechanism seemed to be a general mechanism of degradation of isoregic PEAs whatever their composition. An imidation reaction in one step was proposed, nevertheless the splitting of the relatively weak 
ester bonds followed by cyclization could not be excluded. It can be supposed that the rate of the former step is very slow since no end carboxylic groups could be found on the degraded PEAs and on the residues of degradation. It allowed explaining the higher stability of the syndioregic polymers, since cyclic imides could not be directly obtained from their macromolecular chains. No intermolecular imidation was discussed in the previous papers $[42,43,45]$. This reaction also induces chain scissions and imidic structures, but the latter were not cyclic. To conclude on this part, the higher stability of the syndioregic PEAs compared to isoregic PEAs emphasized the relevance of the polymer synthesis pathway chosen in this work. The length of the diacid unit is decisive to determine the propensity of PEA to degradation. The higher the ester groups content per unit volume, the less stable the polymers are.

The sample weight remaining at the end of the TGA analyze was between $1 \%$ and $7 \%$ of the initial value. The decomposition of each polymer always begins at a much higher temperature than the melting temperature since the gap between $\mathrm{T}_{5 \%}$ and $\mathrm{T}_{\mathrm{m}}$ range between $100^{\circ} \mathrm{C}$ and $150^{\circ} \mathrm{C}$ and was much more for the PEA based on D18:1 (Table 3). As a consequence, all the PEAs can be processed from the melt.

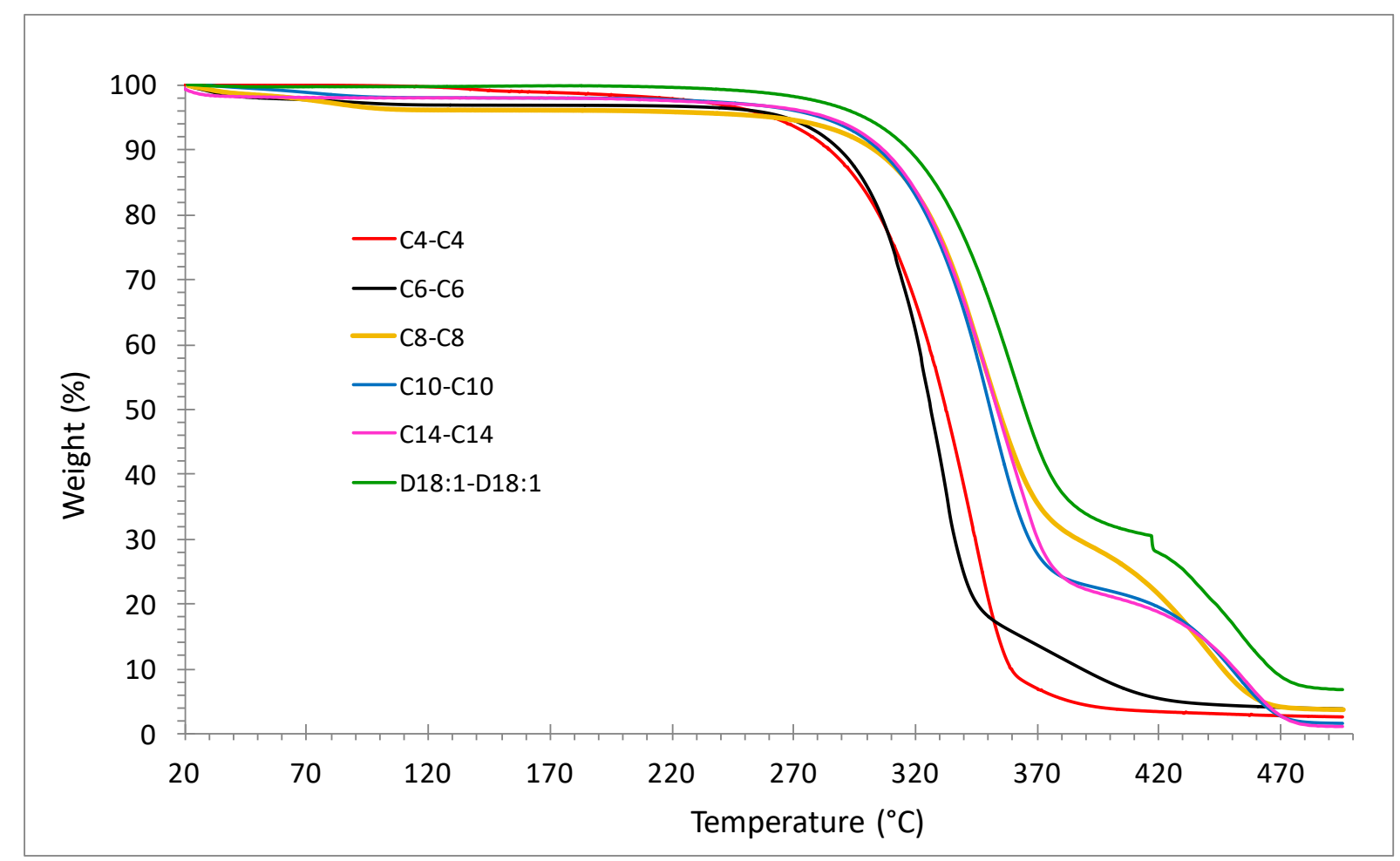

Figure 8: TGA analyses of the PEAs synthesized with $\mathrm{Ti}(\mathrm{OBu})_{4}$ (runs 1 to 6, Table 3) 
The thermal behavior of the polymers was then examined by $\mathrm{DSC}$ from $-80^{\circ} \mathrm{C}$ to $200^{\circ} \mathrm{C}$, i.e at temperatures below their decomposition temperatures. The melting temperatures of runs 1 to 6 range between about $120^{\circ} \mathrm{C}$ and $130^{\circ} \mathrm{C}$, except for the PEAs synthesized from succinic acid and D18:1, which present very particular values. Concerning the polymer issued from D18:1, a very low melting temperature was obtained $\left(\mathrm{T}_{\mathrm{m}}=73.5^{\circ} \mathrm{C}\right)$ and was explained by the presence of the double bonds in the polymer chains, leading to a less tied packing of the chains and so reducing the hydrogen bonds. Conversely, the PEA based on C4 diacid had the highest melting temperature $\left(\mathrm{T}_{\mathrm{m}}=158^{\circ} \mathrm{C}\right)$. This result is probably issued from a dense network of hydrogen bonds due to high amide groups content/unit volume in the polymer. Only for this sample, an exotherm was observed during the heating stage in addition to endotherm (Fig. 9). It corresponds to melt crystallization. When the temperature increased, the polymer chains acquired more mobility, thus they recrystallized from the melt into their most stable possible form then subsequently melted. This kind of behavior was observed for example by Narine on PEAs derived from oleic acid [40]. Moreover, when using a cooling program with a lower rate, exotherms were observed both during the heating and cooling phases. In this case, the glass temperature transition becomes less visible due to the reduction of the amorphous phase amount. Thus, for some PEAs the glass temperature transition was weak and may be poorly visible. A PEA was synthesized using four monomers with a molar ratio equal to 1, two diacids (C4 and D18:1) and their dioldiamide counterparts (run 7, Table 3). However, a drastic decrease of the polymer melting temperature was noted compared to the PEA based on succinic acid. Such result is assigned to a reduced chains packing due to structural differences between the monomers and to the unsaturated structure of D18:1 units hardly compactable. Similar result was obtained polycondensing the C4 acid and the dioldiamide resulting from D18:1 (run 9). In this experiment a catalyst other than $\operatorname{Ti}(\mathrm{OBu})_{4}$ was used, but it will be proved later that it did not induce modification of the polymer features. Thus, in the present investigated examples, it appears that to obtain polymers with the highest $T_{m}$, it is necessary to polymerize only the aliphatic diacid with the dioldiamide corresponding to the same diacid. Similar observations are described in literature [46]. The PEAs endotherms were often broad or had shoulder, highlighting heterogeneous crystallites. The thermogram of run 3 is given as illustration in Fig S18. 


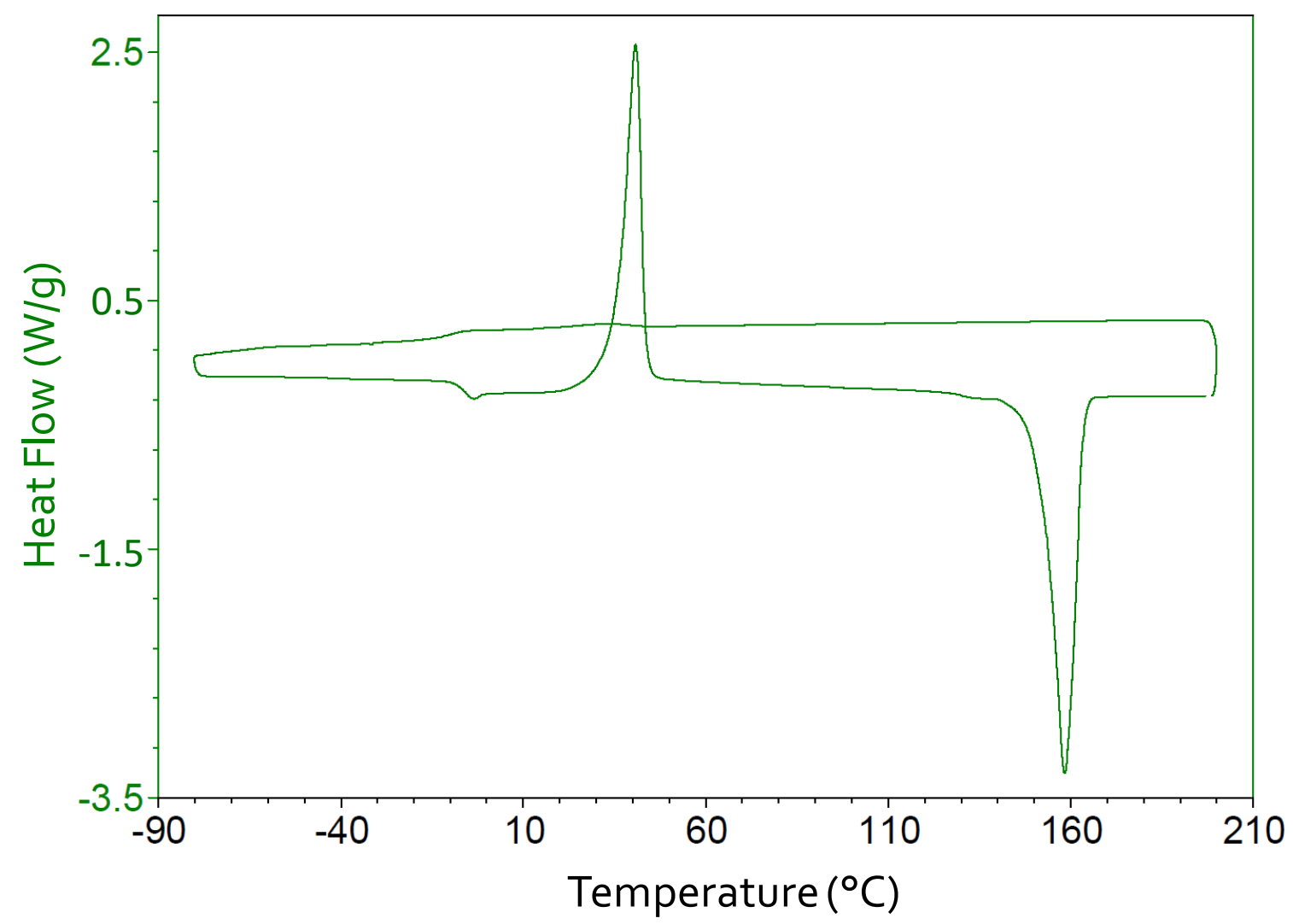

Figure 9: DSC thermogram of PEA synthesized from succinic acid (run 1, Table 3)

The rate of crystallization was defined as the difference between the melting and the crystallization temperatures [47]. Thus, for the run 2 to 6 of Table 3, the temperature gaps range between about $20^{\circ} \mathrm{C}$ and $30^{\circ} \mathrm{C}$. These values suggest high rates of crystallization from the melt. The PEA derived from succinic acid having a melt crystallization was not considered for this comparison. A fast crystallization is an interesting feature for melt processing.

It is interesting to compare our PEAs to PEAs synthesized by polycondensation in bulk of a diacid with an amino alcohol in order to see the influence of the monomers insertion direction on the thermal properties of the polymers. P. Rizzarelli et al. [7] and A. Borriello et al. [48] investigated different amino alcohol. However, only the PEAs synthesized from ethanolamine were discussed here in order to compare polymers of similar structures, thus avoiding the possible influence of the length of the amino alcohol. The polycondensations were performed under nitrogen and were catalyzed by tin (II) 2-ethylhexanoate. The melting temperatures indicated by the two groups were between $104^{\circ} \mathrm{C}$ and $107^{\circ} \mathrm{C}$ for a PEA derived from sebacic acid. In our study, the corresponding PEA $\left(M_{\mathrm{n}}=10000\right.$ g.mol $\left.{ }^{-1}\right)$ had a $\mathrm{T}_{\mathrm{m}}$ equal to $130^{\circ} \mathrm{C}$. 
Only the molar mass of the PEA obtained by A. Borriello et al was specified $\left(M_{\mathrm{n}}=24000\right.$ g.mol $\left.{ }^{-1}\right)$. Therefore, even with a lower molar mass, the PEA synthesized in this study presents a higher melting temperature. To conclude, these comparisons allowed highlighting the importance of the control of the polymer microstructure on its thermal property.

\subsubsection{Influence of the catalyst}

In this work, the use of different catalysts were investigated to synthesize the PEAs. So, in addition of $\mathrm{Ti}(\mathrm{OBu})_{4}$, 1,5,7-Triazabicyclo[4.4.0]dec-5-ene (TBD) and 1-chloro-3-hydroxy1,1,3,3-tetrabutyldistannoxane (CHTD) were also used. TBD is an organocatalyst used to synthesize polyesters [49]. It allowed the synthesis of polymer without metallic residue. If it compares the polymerizations of D18:1 with its dioldiamide counterpart, one performed with $\mathrm{Ti}(\mathrm{OBu})_{4}$ (run 6, Table 3), and the second with TBD (run 8, Table 3), no substantial differences were observed concerning the polymers molar masses and the $T_{m}$ values. A last experiment was realized using CHTD as catalyst, which was synthesized according to a published process [50]. Its synthesis and one of the PEA were detailed is Supporting information. The polymerization of the succinic acid with the corresponding dioldiamide was performed by adapting literature procedure of polyester syntheses [51,52]. The interest of this catalyst is that the second step of the polymerization (under vacuum) is not necessary. As a consequence, only one step under nitrogen was realized. Once again, similar results were obtained if it compares the polymerization catalyzed by CHTD (run 10, Table 3), to the polymerization catalyzed by $\mathrm{Ti}(\mathrm{OBu})_{4}$ (run 1, Table 3). These first assays showed that the synthesis pathway developed in this paper to synthesize PEA can be conducted using different kinds of catalysts.

\subsubsection{Solubility of the PEAs}

The solubility of few PEAs in different solvents was evaluated first at room temperature at a concentration of $10 \mathrm{mg} \cdot \mathrm{mL}^{-1}$. Data are collected in Table 4. Whatever the composition of the PEA, the results are generally the same for the tested samples. The polymers are insoluble in usual solvents of variable polarity, even heating the solutions. However, in the case of DMSO, the solubilization was successful by diluting $\left(\mathrm{c}=2.5\right.$ or $\left.5 \mathrm{mg} \cdot \mathrm{mL}^{-1}\right)$ and heating the solution except for the PEA based on C14. Nevertheless, the clear solutions at room temperature became cloudy with time. To dissolve the polymers at room temperature, it was necessary to use solvents able to break the strong hydrogen bonds between the polymer chains. It can be achieved using hexafluoropropan-2-ol or TFA or formic acid. The PEAs 
could also be solubilized in N-methyl-2-pyrrolidone, except for the PEA derived from C14 acid which is only soluble in hot NMP. These results are consistent with the solubility behavior of usual polyamides, making these PEAs good candidates to substitute polyamides in some applications.

\begin{tabular}{lcccc}
\hline & \multicolumn{4}{c}{ PEA synthesized from ${ }^{\text {a) }}$} \\
& C6 & C8 & C10 & C14 \\
\hline Ethyl acetate & - & - & - & - \\
Acetonitrile & - & - & - & - \\
Water & - & - & - & - \\
Chloroform & - & - & - & - \\
THF & - & - & - & - \\
DMF & - & - & - & - \\
DMSO & - & - & - & - \\
NMP $^{\text {b) }}$ & + & + & + & $+/-$ \\
TFA $^{\text {b) }}$ & + & + & + & + \\
HFIP $^{\text {b) }}$ & + & + & + & + \\
Formic acid $^{\text {C }}$ & + & + & + & + \\
\hline
\end{tabular}

a) respectively runs 2 to 5 of Table 3

${ }^{\text {b) }} \mathrm{NMP}=\mathrm{N}$-methyl-2-pyrrolidone, TFA = trifluoroacetic acid, HFIP = hexafluoropropan-2-ol

$\left.{ }^{c}\right)(+)$ soluble at room temperature, $(+/-)$ soluble in hot solvent, (-) insoluble

Table 4: Tests of PEAs solubility in different solvents $(\mathrm{c}=10 \mathrm{mg} / \mathrm{mL})^{\mathrm{c})}$

\section{Conclusion}

The present work focused on the synthesis of a new library of poly(esteramide)s with a controlled regicity. The work focused on monomers from renewable resources, such as succinic acid and D18:1. In order to control the monomer insertion, monomers with two alcohol functions and two amide functions were synthesized by the reaction of ethanolamine with a diacid. In-depth ${ }^{1} \mathrm{H}$ and ${ }^{13} \mathrm{C}$ NMR versus HSQC NMR analysis allowed probing the reactivity of amine or alcohol or acid functions. In the first step, the formation of amide functions only was demonstrated, leading to pure monomer with end alcohol functions. Then, polycondensations were performed between a diacid and a dioldiamide. SEC analyses were 
conducted and polymers with dispersity lower than 2 were obtained, suggesting the absence of side reaction during the polymerization. A library of new PEAs was thus synthesized with degradation temperature above the one usually observed for aliphatic polyesters, thanks to the formation of a hydrogen bond network between the amide functions born by the polymer. Analysis of the thermal characteristics of this new PEAs family revealed high melting temperature for most of the investigated polymers, associated to a low value of the temperature difference between crystallization and melting. This last observation is an important characteristic for applications of these PEAs in polymer melt processing, suggesting the use of these PEAs as substituent for standard engineering polymers, with similar thermal properties. The regicity control is also participating to the increased melting temperature of these PEAs. The presence of ester functions in the main chain of polymers is an advantage for subsequent degradation of the polymer, an important parameter to consider for the development of new polymers today. The last feature of this synthetic procedure is that its simplicity is compatible with an easy scale up for material production.

\section{References}

1. A. Rodriguez-Galan, L. Franco, J. Puiggali, Degradable poly(ester amide)s for biomedical applications, $\quad$ Polymers 3 (2011) 65-99, https://doi.org/10.3390/polym3010065

2. A. C. Fonseca, M. H. Gil, P. N. Simões, Biodegradable poly(ester amide)s - A remarkable opportunity for the biomedical area: Review on the synthesis, characterization and applications, Progress in Polymer Science 39 (2014) 1291-1311, http://dx.doi.org/10.1016/j.progpolymsci.2013.11.007

3. R. Wang, T. Ren, Y. Bai, Y. Wang, J. Chen, L. Zhang, X. Zhao, One-pot synthesis of biodegradable and linear poly(ester amide)s based on renewable resources, J. Appl. Polym. Sci. 133(22) (2016) 43446, https://doi.org/10.1002/app.43446

4. P-J. Roumanet, F. Laflèche, N. Jarroux, Y. Raoul, S. Claude, P. Guégan, Novel aliphatic polyesters from an oleic acid based monomer. Synthesis, epoxidation, crosslinking and biodegradation, Eur. Polym. J. 49 (2013) 813-822, https://doi.org/10.1016/j.eurpolymj.2012.08.002

5. L. Goujard, P-J. Roumanet, B. Barea, Y. Raoul, F. Ziarelli, J. Le Petit, N. Jarroux, E. Ferre, P. Guégan, Evaluation of the effect of chemical or enzymatic synthesis 
methods on biodegradability of polyesters, J. Polym. Environ. 24 (2016) 64-71, https://doi.org/10.1007/s10924-015-0742-7

6. H. Tetsuka, Y. Doi, H. Abe, Synthesis and thermal properties of novel periodic poly(ester-amide)s derived from adipate, butane-1,4-diamine, and linear aliphatic diols, Macromolecules 39 (2006) 2875-2885, https://doi.org/10.1021/ma052566j

7. P. Rizzarelli, M. Cirica, G. Pastorelli, C. Puglisi, G. Valenti, Aliphatic poly(ester amide)s from sebacic acid and aminoalcohols of different chain length: Synthesis, characterization and soil burial degradation, Polymer Degradation and Stability 121 (2015) 90-99, https://doi.org/10.1016/j.polymdegradstab.2015.08.010

8. K. Marchildon, Polyamides - still strong after seventy years, Macromol. React. Eng. 5 (2011) 22-54, https://doi.org/10.1002/mren.201000017

9. M. Winnacker, B. Rieger, Biobased polyamides: Recent advances in basic and applied research, Macromol. Rapid Commun. 37 (2016) 1391-1413, https://doi.org/10.1002/marc.201600181

10. M. Winnacker, B. Rieger, Poly(ester amide)s: recent insights into synthesis, stability and biomedical applications, Polym. Chem. 7 (2016) 7039-7046, https://doi.org/10.1039/c6py01783e

11. I. Goodman, RN. Vachon, Copolyesteramides-II anionic copolymers of $\varepsilon$-caprolactam with $\varepsilon$-caprolactone preparation and general properties, Eur. Polym. J. 20 (1984) 529537, https://doi.org/10.1016/0014-3057(84)90092-2

12. I. Goodman, RN. Vachon, Copolyesteramides-III. Anionic copolymers of $\varepsilon$ caprolactam with $\varepsilon$-caprolactone. Crystalline character and mechanical properties, Eur. Polym. J. 20 (1984) 539-547, https://doi.org/10.1016/0014-3057(84)90093-4

13. W. H. Carothers, J. W. Hill, Studies of the polymerization and ring formation. XIII. Polyamides and mixed polyester-polyamides, J. Am. Chem. Soc. 54 (1932) 1566-1569, https://doi.org/10.1021/ja01343a049

14. Y. Feng, J. Guo, Biodegradable polydepsipeptides, Int. J. Mol. Sci. 10 (2009) 589615, https://doi.org/10.3390/ijms10020589

15. R. ATM. Van Benthem, Novel hyperbranched resins for coating applications, Progress in Organic Coatings 40 (2000) 203-214, https://doi.org/10.1016/S03009440(00)00122-3

16. D. Chromcová, L. Baslerová, J. Roda, J. Brozek, Polymerization of lactams. 99 Preparation of polyesteramides by the anionic copolymerization of $\varepsilon$-caprolactam and 
E-caprolactone, European Polymer Journal 44 (2008) 1733-1742, https://doi.org/10.1016/j.eurpolymj.2008.03.016

17. J. Luston, J. Kronek, O. Markus, I. Janigová, F. Böhme, Synthesis and polymerization reactions of cyclic iminoethers. 3. Poly(ester amide)s of the AA+BB type on the basis of 2-oxazolines, Polym. Adv. Technol. 18 (2007) 165-172, https://doi.org/10.1002/pat.801

18. F. N. Führer, H. Schlaad, ADMET polymerization of amino-acid-based diene, Macromol. Chem. Phys. 215 (2014) 2268-2273, https://doi.org/10.1002/macp.201400166

19. K. Kempe, Chain and step growth polymerizations of cyclic imino ethers: from poly(2-oxazoline)s to poly(ester amide)s, Macromol. Chem. Phys. 218 (2017) 1700021, https://doi.org/10.1002/macp.201700021

20. P. AJM. de Jongh, P. KC. Paul, E. Khoshdel, P. Wilson, K. Kempe, D. M. Haddleton, High $\mathrm{T}_{\mathrm{g}}$ poly(ester amide)s by melt polycondensation of monomers from renewable resources; citric acid, D-glucono- $\delta$-lactone and amino acids: A DSC study, European Polymer Journal 94 (2017) 11-19, https://doi.org/10.1016/j.eurpolymj.2017.06.040

21. I. Goodman, RJ. Sheanan, Copolyesteramides-V. Hexamethylene adipamide/hexamethylene adipate random and ordered copolymers: preparation and general properties, Eur. Polym. J. 26 (1990) 1081-1088, https://doi.org/10.1016/00143057(90)90007-Q

22. E. Sorta, G. della Fortuna, Poly(ester amide)-polyether block copolymers: preparation and some physicochemical properties, Polymer, 21 (1980) 728-732, https://doi.org/10.1016/0032-3861(80)90287-6

23. I. B. Mansour, K. Alouani, E. Chauveau, V. Martin, F. Schiets, R. Mercier, Synthesis and characterisation of poly(ester-amide)s from aromatic bisoxazoline precursors, European Polymer Journal $46 \quad$ (2010) 814-820, https://doi.org/10.1016/j.eurpolymj.2009.12.014

24. Y. Xia, R. C. Larock, Vegetable oil-based polymeric materials: synthesis, properties, and applications, Green Chem. 12 (2010) 1893-1909, https://doi.org/10.1039/c0gc00264j

25. J. Graca, S. Santos, Linear aliphatic dimeric esters from cork suberin, Biomacromolecules 7 (2006) 2003-2010, https://doi.org/10.1021/bm060174u 
26. A. Cukalovic, C. V. Stevens, Feasibility of production methods for succinic acid derivatives: a marriage of renewable resources and chemical technology, Biofuels, Bioproducts and Biorefining 2 (2008) 505-529, https://doi.org/10.1002/bbb.105

27. J. G. Zeikus, M. K. Jain, P. Elankovan, Biotechnology of succinic acid production and markets for derived industrial products, Appl Microbiol Biotechnol 51 (1999) 545-552, https://doi.org/10.1007/s002530051431

28. H. Song, S. Y. Lee, Production of succinic acid by bacterial fermentation, Enzyme and $\begin{array}{llll}\text { Microbial Technology } & 39 & \text { (2006) 352-361, }\end{array}$ https://doi.org/10.1016/j.enzmictec.2005.11.043

29. B. Cok, I. Tsiropoulos, A. L. Roes, M. K. Patel, Succinic acid production derived from carbohydrates: An energy and greenhouse gas assessment of a platform chemical toward a bio-based economy, Biofuels, Bioprod. Bioref. 8 (2014) 16-29, https://doi.org/10.1002/bbb.1427

30. M. Frauenkron, J-P. Melder, G. Ruider, R. Rossbacher, H. Höke, "Ethanolamines and Propanolamines," in: Ullmann's Encyclopedia of Industrial Chemistry John Wiley \& Sons: New York, 2000.

31. M. Foti, R. Médici, H. J. Ruijssenaars, Biological production of monoethanolamine by engineered Pseudomonas putida S12, Journal of Biotechnology 167 (2013) 344-349, https://doi.org/10.1016/j.jbiotec.2013.07.013

32. A. Jaeger, German Patent DE 1050540 (1959)

33. T. Kagiya, S. Narisawa, T. Maeda, K. Fukui, Preparation of a crystalline poly(esteramide) by the polyaddition reaction of the bisoxazoline and a dicarboxylic acid, J. Polym. Sci. Polym. Lett. B4 (1966) 257-260, https://doi.org/10.1002/pol.1966.110040405

34. L. Néry, H. Lefebvre, A. Fradet, Kinetic and mechanistic studies of carboxylic acidbisoxazoline chain-coupling reactions, Macromol. Chem. Phys. 204 (2003) 17551764, https://doi.org/10.1002/macp.200350036

35. B. M. Culbertson, Cyclic imino ethers in step-growth polymerizations, Prog. Polym. Sci. 27 (2002) 579-626, https://doi.org/10.1016/S0079-6700(01)00053-3

36. T. Loontjens, W. Belt, D. Stanssens, P. Weerts, Synthesis of bisoxazolines and their application as chain extender for poly(ethylene terephtalate), Makromol. Chem., Macromol. Symp. 75 (1993) 211-216, https://doi.org/10.1002/masy.19930750121 
37. Y. Sano, Polymerization of bis( 2-Oxazoline) compounds with dicarboxylic acids, J Polym Sci, Part A, Polym Chem 27 (1989) 2749-2760, https://doi.org/10.1002/pola.1989.080270820

38. Y. Sano, K. Arita, I. Masuda, US Patent 4,474,942 (october 2, 1984)

39. D. Kumar, J. Singh, A. J. Elias, Chiral multidentate oxazoline ligands based on cyclophosphazene cores: synthesis, characterization and complexation studies, Dalton Trans. 43 (2014) 13899-13912, https://doi.org/10.1039/c4dt01741b

40. J. Zuo, S. Li, L. Bouzidi, S. S. Narine, Thermoplastic polyester amides derived from $\begin{array}{lllll}\text { oleic acid, } & \text { Polymer } & 52 & \text { (2011) }\end{array}$ https://doi.org/10.1016/j.polymer.2011.08.002

41. Y. P. Ge, D. Yuan, Z. L. Luo, B. B. Wang, Synthesis and characterization of poly(ester amide) from renewable resources through melt polycondensation, $\begin{array}{llll}\text { eXPRESS } & \text { Polymer } & \text { Letters } & \text { 50-54, }\end{array}$ https://doi.org/10.3144/expresspolymlett.2014.6

42. T. Fey, M. Hölscher, H. Keul, H. Höcker, Alternating poly(ester amide)s from succinic anhydride and $\alpha, \omega$-amino alcohols: synthesis and thermal characterization, Polym. Int. 52 (2003) 1625-1632, https://doi.org/10.1002/pi.1354

43. T. Fey, H. Keul, H. Höcker, Interconversion of alternating poly(ester amide)s and cyclic ester amides from adipic anhydride and $\alpha, \omega$-amino alcohols, Macromol. Chem. Phys. 204 (2003) 591-599, https://doi.org/10.1002/macp.200390021

44. I. Villuendas, J. I. Iribarren, S. Munoz-Guerra, Poly(ester amide)s derived from Ltartaric acid and amino alcohols. 1. regic polymers, Macromolecules 32 (1999) 80158023, https://doi.org/10.1021/ma991050v

45. I. Villuendas, I. Molina, C. Regano, M. Bueno, A. Martinez de Ilarduya, J. A. Galbis, S. Munoz-Guerra, Hydrolytic degradation of poly(ester amide)s made from tartaric and succinic acids: influence of the chemical structure and microstructure on degradation rate, Macromolecules 32 (1999) 8033-8040, https://doi.org/10.1021/ma990407s

46. I. Villuendas, J. J. Bou, A. Rodriguez-Galan, S. Munoz-Guerra, Alternating Copoly(ester amide)s derived from Amino Alcohols and L-Tartaric and Succinic Acids, Macromol. Chem. Phys. 202 (2001) 236-244, https://doi.org/10.1002/15213935(20010101)202:2<236::AID-MACP236>3.0.CO;2-H

47. P. J. M. Serrano, B. A. Van de Werff, Gaymans R J, Alternating polyesteramides based on 1,4-butylene terephthalamide: 3. Alternating polyesteramides based on 
mixtures of linear diols (4NTm,p), Polymer $39 \quad$ (1998) 83-92, https://doi.org/10.1016/S0032-3861(97)00232-2

48. A. Borriello, L. Nicolais, S. J. Huang, Poly(amide-ester)s Derived from Dicarboxylic Acid and Aminoalcohol, Journal of Applied Polymer Science 95 (2005) 362-368, https://doi.org/10.1002/app.21270

49. T. Lebarbé, L. Maisonneuve, T. H. N. Nguyen, B. Gadenne, C. Alfos, H. Cramail, Methyl 10-undecenoate as a raw material for the synthesis of renewable semicrystalline polyesters and poly(ester-amide)s, Polym. Chem. 3 (2012) 2842-2851, https://doi.org/10.1039/c2py20394d

50. J. Otera, N. Dan-oh, H. Nozaki, Novel Template Effects of Distannoxane Catalysts in Highly Efficient Transesterification and Esterification, J. Org. Chem. 56 (1991) 53075311, https://doi.org/10.1021/jo00018a019

51. M. Ueda, H. Takahashi, T. Hayakawa, T. Teranishi, US Patent 6,350,850 B1 (February 26, 2002)

52. M. Ishii, M. Okazaki, Y. Shibasaki, M. Ueda, Convenient Synthesis of Aliphatic Polyesters by Distannoxane-Catalyzed Polycondensation, Biomacromolecules 2 (2001) 1267-1270, https://doi.org/10.1021/bm015576a 


\section{Scheme Captions}

Scheme 1 : Polycondensation of 2,2'-bis(2-oxazoline) and D18:1

Scheme 2 : Branching and cross-linking reactions

Scheme 3 : Synthesis of dioldiamides

\section{Figure Captions}

Figure 1: Different insertion directions of the aminoalcool during the polycondensation

Figure $2:{ }^{1} \mathrm{H}$ NMR spectrum of the PEA synthesized from 2,2'-bis(2-oxazoline) and D18:1 in $\mathrm{CDCl}_{3}$ (run 2, Table 1).

Figure 3: ${ }^{1} \mathrm{H}$ NMR spectrum of (Z) N,N'-bis(2-hydroxyethyl)octadec-9-enediamide in DMSO-D6

Figure 4: ${ }^{1} \mathrm{H}$ NMR spectrum of N,N'-bis(2-hydroxyethyl)butanediamide (HEBDA) in DMSO-D6

Figure 5: Synthesis of HEBDA : kinetic study at $140^{\circ} \mathrm{C}$ and $160^{\circ} \mathrm{C}$.

Figure 6: kinetic study of the amidation reaction of various bio-sourced diacid at $160^{\circ} \mathrm{C}$.

Figure 7: ${ }^{1} \mathrm{H}$ and ${ }^{13} \mathrm{C}$ NMR spectra of PEA resulting from adipic acid and HEHDA in DMSOD6.

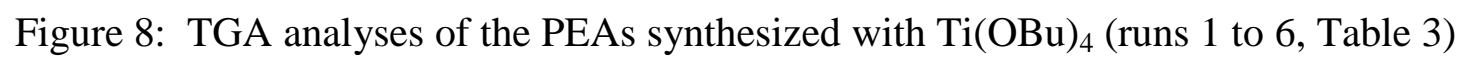

Figure 9: DSC thermogram of PEA synthesized from succinic acid (run 1, Table 3)

\section{Table Captions}

Table 1: Polymerization of 2,2'-bis(2-oxazoline) and D18:1

Table 2: Thermal characteristics of the dioldiamides

Table 3: Polycondensations of a dioldiamide with a diacid

Table 4: Tests of PEAs solubility in different solvents $(\mathrm{c}=10 \mathrm{mg} / \mathrm{mL})^{\mathrm{c})}$ 